\title{
Cardiac Output Assessed by Invasive and Minimally Invasive Techniques
}

\author{
Allison J. Lee, Jennifer Hochman Cohn, and J. Sudharma Ranasinghe \\ Jackson Memorial Hospital, University of Miami, Miami, FL 33136, USA \\ Correspondence should be addressed to Allison J. Lee, alee@med.miami.edu \\ Received 23 December 2010; Accepted 22 March 2011 \\ Academic Editor: Jamal Alhashemi \\ Copyright () 2011 Allison J. Lee et al. This is an open access article distributed under the Creative Commons Attribution License, \\ which permits unrestricted use, distribution, and reproduction in any medium, provided the original work is properly cited. \\ Cardiac output (CO) measurement has long been considered essential to the assessment and guidance of therapeutic decisions \\ in critically ill patients and for patients undergoing certain high-risk surgeries. Despite controversies, complications and inherent \\ errors in measurement, pulmonary artery catheter (PAC) continuous and intermittent bolus techniques of CO measurement \\ continue to be the gold standard. Newer techniques provide less invasive alternatives; however, currently available monitors are \\ unable to provide central circulation pressures or true mixed venous saturations. Esophageal Doppler and pulse contour monitors \\ can predict fluid responsiveness and have been shown to decrease postoperative morbidity. Many minimally invasive techniques \\ continue to suffer from decreased accuracy and reliability under periods of hemodynamic instability, and so few have reached the \\ level of interchangeability with the PAC.
}

\section{Cardiac Output Assessed by Invasive and Minimally Invasive Techniques}

Cardiac output $(\mathrm{CO})$ measurement has long been considered essential to the assessment and guidance of therapeutic decisions in critically ill patients, by providing an indirect indication of systemic oxygen delivery and global tissue perfusion. Perioperatively, $\mathrm{CO}$ monitoring has become virtually routine for certain high-risk patients and in major surgeries, where large fluid shifts are expected.

\section{History}

The technique was first described in 1870 by Adolf Fick [1], who computed an animal's CO by utilizing oxygen concentrations in arterial and venous blood samples, where $\mathrm{CO}$ is equal to oxygen consumption $\left(\mathrm{VO}_{2}\right)$, divided by arterial oxygen content $\left(\mathrm{CaO}_{2}\right)$ minus mixed venous oxygen content $\left(\mathrm{CvO}_{2}\right)[2,3]$

$$
\mathrm{CO}=\frac{\mathrm{VO}_{2}}{\left(\mathrm{CaO}_{2}-\mathrm{CvO}_{2}\right) \times 10}
$$

Pulmonary artery catheterization was first performed experimentally in dogs by Grehant and Quinquaud in 1886, but the technique would not become available to humans for another fifty years [4].

Indicator-dilution techniques later developed. In 1897, Stewart described experiments pioneering the indicatordilution principle, when he injected sodium chloride into the central circulation of animals and measured its subsequent concentration in the femoral artery [5]. Hamilton modified this principle to account for the varying concentrations of diluted injectate over time in human circulation, developing a time concentration curve to reflect this phenomenon [2]. $\mathrm{CO}$ was shown to equal the quantity of indicator dye (indocyanine green) injected, divided by the area under the dilution curve measured downstream, today known as the Stewart-Hamilton equation [5]:

$$
\text { Flow }=\frac{C_{0} V_{0}}{\int c(t) \mathrm{d} t}
$$

where $C_{0}$ denotes initial injectate concentration and $V_{0}$ represents initial injectate volume. The denominator represents the concentration of diluted injectate over time, thus the area under the dilution curve.

Based on the same concept as indicator-dilution methods, Fegler introduced thermodilution (TD) in 1954 by injecting a cold solution as an indicator and measuring changes 
in blood temperature detected distally [6]. In 1970, Swan et al. developed what they termed a "flow-directed balloontipped" multiple lumen catheter, the pulmonary artery catheter (PAC) [7]. The introduction of the PAC enabled physicians to measure $\mathrm{CO}$ by TD both at the bedside and intraoperatively. Forty years later, this method is still considered the clinical gold standard for CO measurement, secondary to its extensive utilization in a variety of clinical settings.

\section{Intermittent Bolus Pulmonary Artery Thermodilution}

The TD technique is founded on the law of conservation of energy [9]. A known amount of cold solution is injected through the proximal port of a PAC into the right atrium, and this solution is detected distally by a thermistor several centimeters from the end of PAC. The change in blood temperature detected causes a change in the thermistor resistance, allowing for the calculation of the area under the TD curve. CO is determined from a modified Stewart-Hamilton equation $[10,11]$ :

$$
\mathrm{CO}=\frac{\mathrm{VI} *(\mathrm{~TB}-\mathrm{TI}) * K 1 * K 2}{\int \Delta \mathrm{TB}(t) \mathrm{d} t},
$$

where VI is injectate volume, TB is blood temperature, TI is injectate temperature, $K 1$ is a density factor: (specific heat (injectate) $\times$ specific gravity (injectate) $) /($ specific heat (blood) $\times$ specific gravity (blood)), and $K 2$ is a computation constant accounting for heat exchange in transit, injection rate, and catheter dead space. The denominator, change of blood temperature as a function of time, reflects the area under the TD curve (Figure 1) [6].

\section{Reliability of Thermodilution}

Despite being considered the gold standard technique for $\mathrm{CO}$ measurement, the reproducibility of TD technique has been heavily scrutinized and, to our knowledge, no data on the subject has been published in the last 20 years. Studies continue to quote statistical significance as demonstrated by Stetz et al. in 1982 [12], where the accuracy of TD was compared to that of Fick and dye-dilution methods. The conclusion was that all three methods are "of equal merit." The intrinsic reproducibility of TD measurements was also analyzed, with the conclusion being that there must be a minimal difference of $12-15 \%$ between three serial CO determinations, to suggest clinical significance [12]. The inherent error of TD measurement, has subsequently been quoted in this manner.

4.1. Sources of Error. Accurate CO estimation can only be made if several assumptions are true. The amount of cold injectate must remain constant between the injection and detection sites. There must be complete mixing of blood and injectate and no fluctuations in baseline blood temperature during measurement [9]. Sources of error may be considered to be technical or intrinsic to certain physiologic states.
Technical errors can be due to loss of indicator before, during, or after injection, variability of temperature and volume of injectate, and thermistor malfunction. Although TD was first performed with $10 \mathrm{~mL}$ of iced 5\% dextrose water, most studies over time have demonstrated no difference in accuracy when iced or room-temperature injectate was used $[2,10,13]$. When using an iced indicator, rewarming of injectate prior to administration and heat transfer during transit can both result in an overestimation of CO. When the volume of indicator injected is less than the assumed amount, an overestimation of CO can occur. Recommended volumes are $10 \mathrm{~mL}$ for adults and $0.15 \mathrm{~mL} / \mathrm{kg}$ for children [6]. A clot over the catheter tip or contact with a vessel wall due to a wedged catheter can insulate the thermistor and result in spurious measurements. An injection time of 4 seconds or less with steady pressure has been recommended to prevent a delayed upstroke of the TD curve. Coiling of the catheter may change the distance from the injection site to the tip and also introduce error [6].

Both physiologic and pathologic states can lead to inaccurate CO measurements. Fluctuations in baseline pulmonary artery temperature occur with cardiac and respiratory oscillations. Rewarming in the initial minutes after cardiac bypass results in a transient decrease in core body temperature as heat distributes to the periphery. Measurements taken at this time can significantly underestimate the true CO [14]. Simultaneous rapid intravenous infusions have also been shown to alter computed CO [2].

It should be emphasized that TD with a PAC measures right ventricular outflow and not systemic CO. Intracardiac shunts can, therefore, lead to inaccurate measurements. In patients with left-to-right shunts, early recirculation of injection results in a subsequent distortion of the downward slope of the TD curve [15]. In the presence of right-to-left shunts, a portion of the indicator will bypass the thermistor, resulting in an overestimation of CO. Both pulmonary and tricuspid valve insufficiencies can likewise lead to unreliable CO determinations. The recirculation of indicator across incompetent valves can overestimate or underestimate CO, depending on the severity of the regurgitation and the underlying systemic $\mathrm{CO}[2]$.

Spontaneous and mechanical ventilation both alter right ventricular output throughout the respiratory cycle more so than left ventricular outflow. Studies evaluating the effects of the mechanical ventilatory cycle on TD measurements reveal inspiratory decreases in right ventricular ejection fraction and subsequent increases in right ventricular end systolic volumes [16]. A fall in left-sided CO, however, is largely prevented by the increase in right ventricular end diastolic volume. These findings explain the greater ventilatory modulation of right ventricular volumes. In the past, measurements taken at the end of expiration were thought to produce the greatest reproducibility. On the contrary, it is argued that more reliable estimations of mean TD CO should be taken from three to four serial CO measurements at different phases of the cycle [6]. Some authors recommend at least eight measurements taken randomly at different times during the ventilatory cycle [16]. 


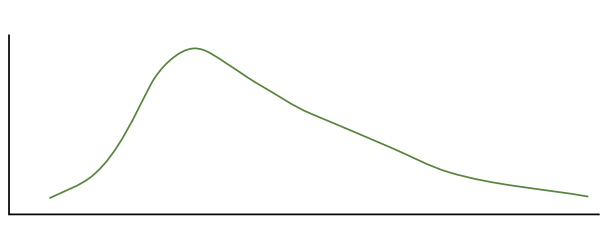

Normal cardiac output

(a)

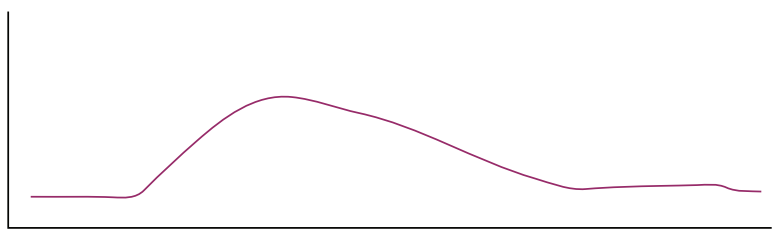

Low cardiac output

(c)

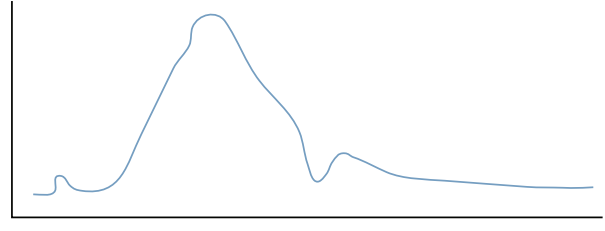

High cardiac output

(b)

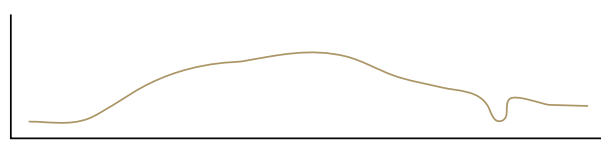

Improper injection technique

(d)

FIgURE 1: Thermodilution cardiac output curves. Used with permission from [8].

\section{Continuous Pulmonary Artery Thermodilution}

Applying the same principles of TD, newer technologies applied to PACs allow continuous CO measurements. By utilizing an electric filament incorporated into the right ventricular portion of the PAC, blood flowing through the right heart is heated intermittently, approximately 15 to $25 \mathrm{~cm}$ proximal to the PAC tip. The resulting thermal signal is measured by a thermistor at the catheter tip. CO measurements by continuous TD have been shown to generally correlate well with intermittent bolus measurement [2]. These catheters provide a continuous trend of $\mathrm{CO}$, decrease operator workload, and possibly reduce infection risk associated with bolus technique. However, since the values displayed are updated every 30 to 60 seconds, what is reflected is the average value for CO measured over the previous 5-15 minutes [9]. Leibowitz and Oropello [17] studied average in vivo time delays associated with sudden changes in CO of critically ill patients. The mean in vivo response times were reported to be $9.3,10.5$, and 11.8 minutes for a 50,75 , and $90 \%$ response, respectively [17]. Due to these inherent time delays, many clinicians argue these continuous monitors should be considered a "continual" rather than continuous real-time monitor [15]. These catheters may therefore be less optimal in detecting and measuring abrupt $\mathrm{CO}$ changes, but could be a more accurate representation of global CO.

5.1. Controversies Regarding Use. In the early 1980's, studies demonstrated improved outcomes with both perioperative and intensive care utilization of pulmonary artery catheterization [17]. However, in 1987, Gore et al. [18] published a study showing that mortality from myocardial infarction actually increased with PAC use. Although this investigation was merely a case-control, chart review study without retrospective risk adjustment, the article led to an editorial calling for a "moratorium" on PAC use [19].

Studies using the PAC to optimize cardiac index, mixed venous oxygen saturation (Sv02), and oxygen delivery have failed to show any reduction in morbidity and mortality of critically ill patients. In the large multicenter, SUPPORT study, a propensity score using multivariable logistic regression, looked at the association between right heart catheterization and specific outcomes. Investigators revealed an increase in 30-day mortality in patients with PACs [20]. The National Heart, Lung, and Blood Institute (NHLBI) and Food and Drug Administration (FDA) have published a consensus statement advocating for RCTs with the PAC in patients with congestive heart failure (CHF), acute respiratory distress syndrome (ARDS), sepsis, and septic shock, as well as low-risk coronary artery bypass graft surgery (CABG) [21].

5.2. Evidence from Randomized Controlled Trials. In 2003, the Canadian Critical Care Clinical Trials Group reported the largest RCT to date, comparing goal-directed therapy using a PAC versus standard care with a central venous catheter (CVC) [22]. There were no differences in hospital mortality, median length of stay (LOS), or one-year survival rates, despite an increased use of inotropic agents, vasodilators, antihypertensives, and erythrocyte and colloid transfusions in the PAC group. PAC-related adverse events occurred in $1.5 \%$ of patients versus $0.7 \%$ related to central venous catheter use alone [22].

In 2005, the PAC-Man study, a RCT done in United Kingdom ICUs, also failed to show evidence of benefit or harm with PAC management [23]. The LOS in the ICU and hospital and days of organ support required were similar in patients managed with and without a PAC. There was a 10\% (46 in 486) incidence of direct complications due to PAC use, the most frequent being hematoma formation, arterial puncture, and arrhythmias. This study, similar to Sandham et al. [22], refuted the claim of increased mortality associated with catheter use. Other studies utilizing a PAC in patients with severe sepsis, septic shock, and/or ARDS failed to show a change in mortality rate [24-26]. In 2006, lowrisk patients undergoing off-pump, beating-heart surgery showed no difference in operative mortality or outcome variables between patients with or without PACs [27]. 
The ESCAPE trial, funded by the NHLBI, evaluated the effectiveness of PACs guiding therapy in patients with severe CHF [28]. The use of the PAC had no effect on the primary endpoint of days alive out of hospital; however, a trend for "greater functional improvement after therapy guided by the PAC" was reported [28]. A concurrent PAC registry was established for hospitalized heart failure patients with a PAC who were not randomized to the trial. The study has been criticized for excluding patients with a higher disease severity and mortality risk [29]. In addition, no treatment protocol or proven therapy was directed towards PAC use [30]. Due to a lack of goal-directed therapy, both groups of patients likely received similar interventions.

A RCT conducted by the NHLBI Acute Respiratory Distress Syndrome (ARDS) Clinical Trials Network in 2006 compared treatment of acute lung injury in patients managed with PACs versus CVCs [25]. There were no statistical differences in mortality in the first 60 days before discharge home, ventilator free days, or LOS in ICU. The PAC group received more red blood cell transfusions and had approximately twice as many catheter-related complications, most commonly arrhythmias.

Why is it that, despite such detailed hemodynamic information, PACs fail to improve patient outcomes? One suggestion is that the lack of goal-directed therapy tailored towards PAC use has prevented us from altering morbidity and mortality. Pulmonary artery catheterization should be seen as a diagnostic tool and not mistaken to be therapeutic [31].

\section{Minimally and Noninvasive Techniques}

Although TD may be considered the gold standard for CO measurement, its use is limited, mainly because of the associated risks of pulmonary artery catheterization (arrhythmias, valvular lesions, infection, pulmonary emboli, pulmonary infarction, and pulmonary artery rupture). Additional costs are also significant. The ideal technique for CO measurement is minimally or noninvasive, is continuous, does not require calibration, and is accurate, reproducible, and reliable during various physiologic states [32]. A multitude of new technologies for $\mathrm{CO}$ measurement have been developed and are now available for clinical use (Table 1).

6.1. Methods of Comparison. Studies of reliability, accuracy, and precision of newer methods of CO measurement generally involve a comparison with more established techniques, such as TD. In the past, correlation and regression analysis was used, however, Bland-Altman analysis has become the preferred method of statistical analysis for determining level of agreement. The difference between comparative measurement is plotted (the bias) against the mean values of each pair of readings. The standard deviation (SD) of each bias measurement is calculated and 95\% confidence limits drawn $(\mu \pm 2 \mathrm{SD})$. The latter is the limits of agreement, upon which a determination of precision is based [33].

L. A. H. Critchley and J. A. J. H. Critchley [33] performed a meta-analysis and found wide variations in the presentation of statistical data for comparison studies. They advocated that studies present the mean $\mathrm{CO}(\mu)$, the bias, the limits of agreement (95\% C.I.), and the percentage error $( \pm 2 \mathrm{SD} / \mu)$ and concluded that acceptance of a new technique should rely on limits of agreement of up to $\pm 30 \%$. They point out that the Bland-Altman method does not compensate for the magnitude of the measurements and the size of the error and suggest that percentage error be calculated for each set of data as opposed to calculating it one time from the averaged data.

\section{Pulse Power Analysis}

Pulse power analysis is based on the theory that fluctuations of blood pressure about the mean are directly related to the stroke volume (SV) ejected into the arterial system [34]. Accuracy of measurement is complicated by several factors.

(i) Nonlinear compliance of the arterial wall. Decreased aortic compliance occurs at higher than at lower blood pressures (BPs).

(ii) Wave reflection, since pulse pressure detected in a peripheral artery is a composite of the pressure wave from ejection from the heart and the reflected pressure wave from the distal arterial tree. Changes in systemic vascular resistance (SVR) affect the reflected wave augmentation of the arterial pressure. The size of the reflected waves is also found to vary with the sampling site proximity to the central circulation and patient age.

(iii) Damping of the transducer system.

(iv) Aortic systolic outflow. Filling is pulsatile; however, outflow tends to be continuous [34].

The LiDCO method of pulse power analysis utilizes a proprietary autocorrelation algorithm (PulseCO (LiDCO, Cambridge, UK)) which addresses the factors mentioned above. The assumption made is that, following calibration and correction for compliance, there is conservation of mass/power and so a linear relationship exists between net power and net flow. Autocorrelation allows for the determination of the beat period as well as the net power change across the whole beat from the stroke volume. As a result, the effect of reflected waves is negated. Since the method is time based, the effects of arterial damping are minimized. Apart from extreme conditions, the pulse power tends to remain the same regardless of the degree of damping [34].

The LiDCO plus (Cambridge, UK) system is coupled to a lithium dilution system, a technique first described by Linton et al. [35] in 1993. Either central or peripheral venous access may be used in addition to a peripheral arterial line, to which a disposable lithium sensitive sensor is attached. The sensor membrane contains an ionophore which is selectively permeable to lithium [36]. The membrane voltage is related to the plasma lithium concentration using the Nernst equation. The voltage is amplified and digitalized for analysis. Sodium supplies the baseline voltage in the absence of lithium. 
TABLE 1: Comparison of minimally invasive cardiac output monitoring techniques (CI: cardiac index, HR: heart rate, and ECG: electrocardiogram).

\begin{tabular}{|c|c|c|c|c|}
\hline Technique & Advantages & $\begin{array}{l}\text { Additional } \\
\text { variables }\end{array}$ & Invasiveness & Limitations \\
\hline \multirow[t]{2}{*}{ LiDCO plus } & Continuous CO measurement & SV & Arterial line & Requires good fidelity of arterial waveform \\
\hline & Useful in goal-directed therapy & SVV & $\begin{array}{l}\text { Peripheral or } \\
\text { central venous line }\end{array}$ & $\begin{array}{l}\text { Calibration affected by neuromuscular blockers } \\
\text { Contraindicated in lithium therapy } \\
\text { Requires transpulmonary lithium dilution calibration }\end{array}$ \\
\hline \multirow[t]{4}{*}{ PiCCO plus } & Continuous CO measurement & GEDV & Arterial line & Requires good fidelity of arterial waveform \\
\hline & & EVLV & & Requires transpulmonary thermodilution calibration \\
\hline & & SVV & & \\
\hline & & PPV & & \\
\hline FloTrac/Vigileo & $\begin{array}{l}\text { Continuous CO measurement } \\
\text { No calibration required }\end{array}$ & SVV & Arterial line & Requires good fidelity of arterial waveform \\
\hline \multirow[t]{2}{*}{ NICO } & Ease of use & Shunt & $\begin{array}{l}\text { Endotracheal } \\
\text { intubation }\end{array}$ & Affected by changes in dead space or V/Q matching \\
\hline & & $\begin{array}{l}\text { Ventilatory } \\
\text { variables }\end{array}$ & $\begin{array}{l}\text { Valid only with } \\
\mathrm{PaCO}_{2}>30 \mathrm{mmHg}\end{array}$ & \\
\hline \multirow[t]{4}{*}{ Bioimpedance } & Noninvasive & & $\begin{array}{l}\text { Cutaneous } \\
\text { electrodes }\end{array}$ & Affected by electrical noise, movement \\
\hline & Continuous CO measurement & & & Electrode contact affected by temperature and humidity \\
\hline & & & & Requires hemodynamic stability \\
\hline & & & & Not useful in dysrhythmias \\
\hline Bioreactance & $\begin{array}{l}\text { Noninvasive Continuous CO } \\
\text { measurement }\end{array}$ & & $\begin{array}{l}\text { Cutaneous } \\
\text { electrodes }\end{array}$ & \\
\hline \multirow[t]{4}{*}{ ECOM } & & SV & $\begin{array}{l}\text { Endotracheal } \\
\text { intubation }\end{array}$ & Coronary blood flow not recorded \\
\hline & & $\mathrm{CI}$ & & Electrocautery produces interference \\
\hline & & SVR & & No fully validated human studies \\
\hline & & HR, ECG & & \\
\hline \multirow[t]{3}{*}{$\begin{array}{l}\text { Ultrasound } \\
\text { dilution }\end{array}$} & $\begin{array}{l}\text { Measures flow in ECMO and } \\
\text { hemodialysis circuits }\end{array}$ & & Arterial line & Fluid overload with saline injection in sensitive patients \\
\hline & & & $\begin{array}{l}\text { Central venous } \\
\text { catheterization }\end{array}$ & Errors from indicator loss in inadequate lung perfusion \\
\hline & & & & Errors in the presence of septal defects \\
\hline TEE & $\begin{array}{l}\text { Used to evaluate cardiac } \\
\text { anatomy and function, preload, } \\
\text { and myocardial ischemia }\end{array}$ & SV & Esophageal probe & Mainly used perioperatively \\
\hline \multirow[t]{2}{*}{$\begin{array}{l}\text { Esophageal } \\
\text { Doppler }\end{array}$} & Useful in goal-directed therapy & SV & Esophageal probe & Measures only descending aortic flow \\
\hline & & & & Assumptions about aortic size may be erroneous \\
\hline
\end{tabular}

The LiDCO plus monitor requires CO calibration with lithium dilution once every eight hours according to the manufacturer. It has been suggested, however, based on recent data, that repeat calibration should take place during major hemodynamic changes [37]. Cecconi et al. [38] concluded that, for good precision, three lithium dilution measurements should be performed. During calibration, isotonic lithium chloride $(150 \mathrm{mM})$ is given intravenously (0.02 to $0.04 \mathrm{mmol} / \mathrm{kg}$ ). CO is derived from the dose and the area under the concentration-time curve. Since lithium is only distributed in the plasma fraction of blood, for the determination of $\mathrm{CO}$, blood flow is determined by dividing plasma flow by 1-packed cell volume, assessed on the basis of hemoglobin/33 [2].

The accuracy of the Pulse CO algorithm may be compromised under the following circumstances:

(i) aortic valve regurgitation,

(ii) post-aortic reconstruction,

(iii) intra-aortic balloon pump, 
(iv) highly damped peripheral arterial lines,

(v) severe peripheral arterial vasoconstriction,

(vi) inaccurate sodium and hemoglobin measurements,

(vii) arrhythmias,

(viii) intra- or extracardiac shunts.

In addition, each $1 \mathrm{~g} / \mathrm{dL}$ difference in hemoglobin artifactually results in a 4\% change in the CO measurement [39].

Lithium therapy is a contraindication to the use of LiDCO, as overestimation of CO occurs with elevated background levels. Some nondepolarizing muscle relaxants contain high levels of quaternary ammonium residues, causing the electrode to drift. Recalibration is recommended prior to injection of the drugs or after the peak concentration has fallen. Bolus dosing is also recommended if nondepolarizing muscle relaxant use cannot be avoided.

The safety of lithium use has been well established. Since lithium does not occur naturally in plasma, does not bind to plasma or tissue proteins, and is not lost in passage through the pulmonary circulation, tiny doses may be used. Levels achieved are $<1 \%$ of therapeutic levels used during treatment of mania with lithium carbonate [36].

For the newer LiDCO rapid (Cambridge, UK), lithium dilution has been replaced with a nomogram which has been derived from in vivo data, to estimate CO. The system features simplicity and ease of use. It was designed to provide reliable hemodynamic trends, which would be useful for goal-directed fluid therapy. In a clinical setting where absolute values for SV and SVR are required, a calibrated, system is warranted [40].

7.1. Validation Studies. Investigators studying small patient populations under different clinical settings and with different reference standards have reported variable findings regarding the accuracy of the LiDCO system. While some have suggested acceptable accuracy [41-44], others have found unacceptable accuracy compared to PAC-derived CO $[45,46]$.

Linton et al. [35] studied 9 patients immediately aftercardiac-surgery and reported good correlation $(r=0.89)$ and a bias $0.3(0.5) \mathrm{L} / \mathrm{min}$ between LiDCO and intermittent bolus pulmonary artery TD (PATD). Costa et al. [47] reported agreement between LiDCO and intermittent PATD in 23 after-liver-transplant patients exhibiting the typical hyperdynamic circulation; the reported bias and 95\% limit of agreement for the PAC versus $\mathrm{PulseCO}_{\mathrm{Li}}$ were $0.29 \mathrm{~L} / \mathrm{min}$ $(r=0.85)$ with a percentage error of $16.8 \%$.

The validity of the device has also been studied in pediatric patients. Kim et al. [48] reported good correlation $(r=0.94)$ with PATD in 20 children (age range 2.5-15.5 years) undergoing cardiac catheterization. In smaller children $(<20 \mathrm{~kg})$, a separate analysis still showed good correlation (0.89). Linton et al. [49] compared the device against transpulmonary TD in 20 pediatric patients (age range 5 days -9 years) and also reported good accuracy $(r=0.96)$.

Yamashita et al. [46] compared bolus PATD with the PulseCO, calibrated with CO by the TD method in patients during cardiac-surgery. They found poor correlation $(r=$
0.49-0.55) and large bias (0.3-0.76), concluding that the methods were not interchangeable. In an observational study of 8 after-cardiac-surgery patients, McCoy et al. [45] compared continuous cardiac index monitoring (CCI) with LiDCO, using a peripheral iv line for indicator delivery. The investigators found minimal bias $(-0.01)$ but wide $95 \%$ limits of agreement with respect to the mean, suggestive of clinically significant differences.

In a randomized controlled trial, Pearse et al. [50] used LiDCO to guide goal-directed therapy (GDT) in high-risk surgical patients. The outcome was fewer complications and shorter length of hospital stay in the GDT group.

Costa et al. [51] carried out comparisons between the LiDCO rapid and intermittent and continuous PATD in 10 after-liver-transplant patients. Their preliminary data showed that, the LiDCO rapid provided acceptable readings, with percentage errors of 26 and $30 \%$, respectively, compared with intermittent and continuous PATD.

Multiple studies are ongoing using the LiDCO rapid to gauge fluid responsiveness and guide fluid management. [52-54]. The LiDCO rapid is also currently being used in a large government-supported multicenter trial currently underway in the UK, OPTIMISE, aimed at improving surgical outcomes by optimizing cardiovascular management [55].

\section{Pulse Contour Analysis}

Pulse contour analysis for CO measurement is based on the hypothesis that the area under the curve of the systolic part of the arterial pressure waveform is proportional to the SV [56]. Wesseling et al. [57] developed the first successful algorithms in the 1970's, which continuously analyze the pressure waveform from an arterial line. The area under the systolic portion of the arterial pulse wave (measured from the end of diastole to the end of the ejection phase) divided by the aortic impedance gives a measure of the stroke volume, which multiplied by the heart rate gives the cardiac output.

8.1. The PiCCO System. The PiCCO system (PULSION Medical Systems) is the first pulse contour device to be introduced into clinical practice $[4,56]$. In 2007, the PiCCO2 replaced the PiCCO.

External manual calibration of the system is performed via transpulmonary TD every eight hours, or up to hourly during periods of hemodynamic instability [58, 59]. Blood temperature changes from a thermo-indicator solution injected via a CVC are detected by a thermistor-tipped catheter, typically placed in the femoral artery. Alternatively, the radial, axillary, or brachial artery may be used; however, longer catheters are required to adequately assess the aortic pressure wave signal from more distal sites. Although accuracy of the transpulmonary TD technique may be affected by the longer transit time, errors due to airway pressure variation are eliminated. The calibration is repeated three to five times to obtain a calibration factor for calculation of continuous $\mathrm{CO}$, intrathoracic blood volume (ITBV), and extravascular lung water (EVLW). 
Global end-diastolic volume (GEDV) is also measured and, together with ITBV, is representative of cardiac preload and EVLW. EVLW, comprising intracellular, interstitial, and intra-alveolar water, is measured intermittently using transpulmonary TD as a means of quantifying pulmonary edema [60]. Systolic pressure variation and stroke volume variation (SVV) provide information about volume status in mechanically ventilated patients [32].

8.2. Limitations. The accuracy of analysis is influenced by vascular compliance, aortic impedance, and peripheral arterial resistance. Second generations of the system software address issues related to differences in individual patients' aortic compliance and now analyze the shape of the waveform and the pulsatile systolic area [61].

Results may be altered secondary to technical problems such as air bubbles in the system, clotting of the catheter, and inadequate indicator. Problems with analysis are also seen with severe arrhythmias, raised EVLW (requiring more indicator), aortic aneurysm (causes ITBV and GEDV to be overestimated), severe valve insufficiency (CO is correct, but preload is overestimated), and rapidly changing body temperature. Recirculation of thermo-indicator may occur in patients with intracardiac shunts and in pediatric patients with open ductus Botalli [60].

8.3. Validation Studies. The pulse contour analysis method has largely been found to correlate well against pulmonary artery thermodilution (PATD) in numerous studies under varying conditions, including coronary artery bypass grafting (CABG) [62-65]. Some bias should be recognized, however, since TD is required for calibration [66]. Other investigators have reported large discrepancies between the two techniques. Halvorsen et al. [67] reported unacceptably large discrepancies with the PATD during off-pump CABG. For lung transplantation, good correlation was found between PiCCO and TD [68]. Significant errors during periods of hemodynamic instability, with the need for repeated recalibration has been reported [69]. In burn patients, good correlation during low to normal $\mathrm{CO}$ was reported; however, greater discrepancy was seen at high cardiac indices [70].

\section{FloTrac/Vigileo}

The FloTrac Vigileo (Edwards Lifesciences, LLC, Irvine Calif, USA) is another pulse contour device, which was first introduced in April, 2005 [4]. The device provides continuous CO measurement from a proprietary FloTrac sensor attached to a standard peripheral arterial catheter, which is connected to the Vigileo monitor. Calculations of SVR and SVV are also displayed. A significant feature of the system is that, unlike PiCCO and Pulse CO, external calibration is not required as the algorithm performs its own calibration using patient demographics and waveform analysis [4]. Notably, no central venous line is required.

The FloTrac algorithm integrates multiple characteristics of the arterial pressure waveform with patient specific demographic data. Parameters include heart rate (HR), the sta- ndard deviation of the arterial pressure, a scale factor proportional to vascular and peripheral resistance combined over the arterial pressure waveform (mean, standard deviation, skewness and kurtosis), pressure-dependent Windkessel, compliance and body surface area [71]. The standard deviation of pulse pressures sampled over 20 seconds is correlated with a predicted SV based on demographic data (age, gender, height, and weight) and extrasystoles and other minor artifacts are eliminated via a beat-detection algorithm [37]. Impedance is also determined from the demographic data. Vascular compliance and resistance are derived from arterial waveform analysis [56].

Second generation versions (1.07 or later) undergo calibration every minute, with improved CO measurement compared with earlier versions [37]. The third generation device, with its Dynamic Tone Technology, is purported to use additional physiologic variables, with automatic adjustment for changes in vascular tone [72]. The third generation is undergoing investigations during hemodynamic instability, such as sepsis and acute circulatory failure [73]. When used in conjunction with a central venous pressure catheter, systemic vascular resistance (SVR) and systemic vascular resistance index (SVRI) may be calculated [71].

9.1. Limitations. Since the calculations depend on the fidelity of the waveform, good arterial signal quality is critical to accuracy of CO measurement. Unreliable measurements are seen in the presence of arrhythmias and during intra-aortic balloon pump use. Although any arterial site may be cannulated, Compton et al. [74] found errors introduced when different sites had mean arterial pressure (MAP) differences of $5 \mathrm{mmHg}$ or more. Mayer et al. [75] reported the percentage error for the FloTrac/Vigileo in obese patients, with their altered arterial compliance, to be slightly higher than that in nonobese when compared with pulmonary artery TD.

9.2. Validation Studies. Although some investigators have reported that the FloTrac appears to be reliable in several situations, its reliability is questioned in hemodynamically unstable patients [74, 76]. Manecke and Auger [77] found satisfactory correlation with PATD for clinical use in aftercardiac-surgery patients, and in a multicenter trial, McGee et al. reported the FloTrac to be comparable to PATD in critically ill patients [78].

Biancofiore et al. [79] found limited accuracy in patients with low SVR who were undergoing liver surgery. Similarly, Matthieu et al. [80] and Krejci et al. [81] found poor agreement in liver-transplant patients with low SVR compared with PATD. Hamm et al. [71] compared the device with instantaneous readings from a pulmonary artery catheter in nine patients undergoing $C A B G$ and concluded that the two were not clinically equivalent. Sakka et al. concluded that transpulmonary TD was more accurate than with FloTrac in septic patients [82].

The manufacturer reports that the system's third generation algorithm (software version 3.02) has broadened its database to include more patients with hyperdynamic conditions and is undergoing investigation [72]. Mayer et al. [83] found only moderate correlation with PATD (overall 
percentage error of $46 \%$ ) in patients undergoing CABG with software version 1.03; however, they later reported percentage errors of $28.3 \%$ and $20.7 \%$ intraoperatively and ICU, respectively, when studying the 1.1 software version in a similar patient population [84].

Further studies are warranted to validate the device's reliability under varying physiologic states. Hofer et al. [85] compared the device with the PiCCO to determine how well fluid responsiveness could be predicted using SVV and found similar accuracy. Suehiro and Okutani [86] concluded that SVV as measured by the FloTrac system was able to predict fluid responsiveness in patients on one lung ventilation. High risk patients undergoing major abdominal surgery who received goal-directed fluid therapy using the FloTrac/Vigileo device (software version 1.14) were found to have fewer complications and decreased hospital LOS [87].

\section{The NICO System: Fick's Principle Using Carbon Dioxide}

The NICO system (Novametrix Medical Systems, Wallingford, Conn, USA), first introduced in 1999 [4], uses the differential Fick partial rebreathing technique to measure CO in intubated, sedated, mechanically ventilated patients.

Fick's principle, using $\mathrm{CO}_{2}$ as an indicator, is rewritten as follows:

$$
\mathrm{CO}=\frac{\mathrm{VCO}_{2}}{\mathrm{Cv}_{\mathrm{CO}_{2}}-\mathrm{Ca}_{\mathrm{CO}_{2}}},
$$

where $\mathrm{VCO}_{2}$ is elimination of $\mathrm{Ca}_{\mathrm{CO}_{2}}$ and $\mathrm{Cv}_{\mathrm{CO}_{2}}$ is arterial and venous $\mathrm{CO}_{2}$ content, respectively.

$\mathrm{Ca}_{\mathrm{CO}_{2}}$ may be calculated from the $\mathrm{PaCO}_{2}$ or estimated from the end-tidal $\mathrm{CO}_{2}$. Diffusion abnormalities limit the accuracy of estimation [32]. $\mathrm{VCO}_{2}$ is calculated from the dif ference between inspired and expired $\mathrm{CO}_{2}$ content. $\mathrm{Cv}_{\mathrm{CO}_{2}}$ is estimated by using a partial rebreathing technique.

A proprietary disposable rebreathing loop is attached to the ventilator circuit, in addition to a mainstream infrared $\mathrm{CO}_{2}$ sensor, a fixed orifice differential pressure pneumotachometer, and a rebreathing valve. Every three minutes, partial rebreathing is initiated by opening the rebreathing valve, which adds $150 \mathrm{~mL}$ of dead space to the circuit. The difference between normal and rebreathing ratios are used to calculate pulmonary blood flow $[4,88]$. Shunt correction is carried out using Nunn's isoshunt curves, a series of curves that describe the relationship between $\mathrm{PaO}_{2}$ and $\mathrm{FiO}_{2}$ for different levels of intrapulmonary shunt. Shunt is determined by using the $\mathrm{PaO}_{2}$ and $\mathrm{FiO}_{2}$.

The intubated patients must be able to tolerate the brief period of rebreathing. Ventilator settings may need adjustment due to the at least $35 \mathrm{~mL}$ of increased dead space introduced.

10.1. Limitations. The normal difference between mixed venous and arterial $\mathrm{CO}_{2}$ tension is approximately $6 \mathrm{mmHg}$. Any increase, due, for example, to increased dead space, would lead to changes in the calculated $\mathrm{CO}$ too. The $\mathrm{PaCO}_{2}$ and $\mathrm{PvCO}_{2}$ relationship is only valid when the $\mathrm{PaCO}_{2}$ is more than $30 \mathrm{mmHg}$ and when the $\mathrm{CO}_{2}-\mathrm{Hgb}$ dissociation curve is linear. Hyperventilation to a $\mathrm{PaCO}_{2}<30 \mathrm{mmHg}$ would lead to inaccuracies in CO measurement. Since only nonshunted blood is measured, the shunt fraction must be estimated for an accurate measure of $\mathrm{CO}$. The shunt fraction is estimated using the shunt equation:

$$
\frac{Q_{s}}{Q_{T}}=\frac{\mathrm{CcO}_{2}-\mathrm{CaO}_{2}}{\mathrm{Cc}_{\mathrm{O}_{2}}-\mathrm{CvO}_{2}}
$$

where $\mathrm{CaO}_{2}, \mathrm{CvO}_{2}$, and $\mathrm{CaO}_{2}$ are the end-capillary, venous, and arterial oxygen content. To measure these noninvasively, Nunn's isoshunt plots are used.

10.2. Validation Studies. Variable results have been published using this technique, with many studies involving patients with varied degrees of intrapulmonary shunt in settings from cardiac-surgery or in hemodynamically unstable ICU patients [32]. Moderate agreement during thoracic surgery was found compared with pulmonary artery TD [89].

Kotake et al. [90] found improved correlation with TD with newer software versions compared with previous studies in patients undergoing abdominal aortic aneurysm repair [91]; however, they concluded that the technology still has not reached the level of interchangeability. In a small study of patients undergoing hip replacement, NICO was compared to TD and a slight underestimation was found, with a small degree of bias. For off-pump CABG patients, investigators concluded that NICO reliably and more rapidly measured CO compared with TD. The authors reported the tendency to underestimation perioperatively, but overestimation in the postoperative period. The limits of agreement were reported to be larger intraoperatively than postoperatively [92]. Similar values were obtained from NICO and PATD for patients before undergoing cardiopulmonary bypass (CPB); however, after separation, NICO tended to underestimate CO [93]. Other investigators comparing NICO and TD for major surgery or the ICU found that NICO slightly underestimated CO compared to TD [94]. Following CABG, NICO had insufficient agreement with TD, as opposed to pulse contour [95]. NICO was found to underestimate CO compared with TD in ICU patients after cardiac-surgery and found least suitable where CO was high [96]. Poor agreement was reported in a similar patient group [97]. Decreased correlation has been reported in the setting of high $\mathrm{CO}$, decreased minute ventilation, increased intrapulmonary shunt, or severe chest trauma [32]. Rocco et al. [98] reported bias of $-2.3 \mathrm{~L} / \mathrm{min}$ when $Q_{s} / Q_{p}$ exceeded $35 \%$.

\section{Thoracic Bioimpedance}

Thoracic bioimpedance (TEB) is the least invasive of the CO monitors. The technology was first developed by Kubicek et al. [99] in the 1960's, with the initial testing being carried out on astronauts [100]. The basis for its use was later pioneered by Lababidi et al. [101] in 1970, with subsequent improvements carried out over the following decades, based on animal and human research. The technique finally became 
popularized based on studies by Shoemaker et al. in the 1990's [100, 102].

The underlying theory is that the thorax is a cylinder perfused with fluid (blood) which has a specific resistivity. Bioimpedance is the electrical resistance to a high-frequency low-amplitude current transmitted from electrodes placed on the upper and lower thorax [32]. Typically, six electrodes are placed-two on either side of the neck and four in the lower thorax. Current transmitted from the outermost surface electrodes is sensed by the innermost set of surface electrodes. The impedance $\left(Z_{o}\right)$ is calculated from the voltage changes, which are indirectly proportional to the volume of fluid in the thorax, such that increased fluid results in lower TEB [103]. Blood flow from the aorta is primarily responsible for the change in impedance. Stroke volume is estimated based on the formula

$$
\mathrm{SV}=\frac{\rho\left(L^{2}\right)}{\left(Z_{\Phi}^{2}\right)} \cdot\left[\operatorname{VET}_{x} \frac{\left(d_{z}\right)}{\left(d t_{\max }\right)}\right],
$$

where $\rho$ is the resistivity of blood $(\mathrm{ohm}-\mathrm{cm}), L$ is the distance between electrodes $(\mathrm{cm}), Z_{\Phi}$ is the mean thoracic impedance between electrodes (ohm), VET is the ventricular ejection time $(\mathrm{sec})$, and $\left(d_{z} / d_{t}\right)_{\max }$ is the maximum negative slope of the bioimpedance signal $(\mathrm{ohm} / \mathrm{sec})$ [89]. Several hemodynamic parameters may be calculated using HR and noninvasive blood pressure, together with the SV [103].

11.1. Limitations. TEB is affected by a number of factors [32]:

(i) changes in tissue fluid volume,

(ii) respiration-induced changes in the volume of pulmonary and venous ("noise" must be filtered out from the desired changes in volumetric blood flow of the aorta),

(iii) changes in electrode contact or position,

(iv) arrhythmias - the VET is determined using the interval between QRS complexes,

(v) acute changes in tissue water, for example, pulmonary or chest wall edema or pleural effusions,

(vi) noise from electrocautery, mechanical ventilation and surgical manipulation,

(vii) changes in myocardial contractility, for example, from anesthetic drugs or ischemia.

11.2. Validation Studies. Several investigators found that TEB compared favorably with PATD in varying settings including during cardiac catheterization, surgical patients, and emergency room patients [102, 104-108]. Van De Water et al. [109] found the TEB compared favorably with TD in post cardiac surgical patients. Kööbi et al. [110], using whole-body impedance cardiography in CABG patients, reported excellent repeatability which allowed for continuous monitoring. Spiess et al. [111] used BioZ (SonoSite Inc, Bothell, Wash,USA) intraoperatively for patients undergoing CABG and found that the technique initially compared well with TD, but, immediately postoperatively, the Bland-
Altman analysis was not as robust. Of note, good correlation was seen during opening of the chest. Spinale et al. [112] used TEB for post-CABG patients and found good correlation with TD but poor correlation in patients who developed severe tachycardia and frequent arrhythmias.

Several investigators have found poor reliability and poor correlation with PATD in after-cardiac-surgery, the critically ill and the elderly [113-115]. In a meta-analysis performed by Rotcajg et al. [116], the conclusion was that TEB might be useful for trend analysis but not diagnostic interpretation. Correlation appeared to be better with repeated measurement designs. Atherosclerotic changes in the aorta of elderly patients reduces the Windkessel effect and contributes to increased inaccuracy [114].

TEB appears unlikely to become a routine monitor of CO for anesthesia or critical care unless further refinements in signal processing occur.

\section{Thoracic Bioreactance}

Thoracic bioreactance technology developed as a refinement of TEB. Bioreactance analyses beat-to-beat changes in the phase of electrical voltage signal relative to the applied current signal across the thorax. Changes in intrathoracic volume produce variations in electrical capacitive and inductive properties (bioreactance). The techniques for detecting relative phase shifts are powerful and less affected by noise and external interference [115]. Thoracic bioreactance technology is commercially available as the NICOM system (Cheetah Medical Inc., Indianapolis, Ind, USA). Two dualelectrode stickers are placed on either side of the thoraxone electrode is used to inject the sine-wave high-frequency $(75 \mathrm{kHz})$ current into the body and the other is used by the voltage input amplifier [115]. The final measurement is determined by averaging the 2 signals.

12.1. Validation Studies. Several validation studies of thoracic bioreactance have been conducted, using continuous PATD as the reference continuous technique. Investigators report good correlation between the two methods $(r=$ 0.64-0.9) and minimal bias [115-117]. Comparisons are limited by differences in intrinsic variability of measurements of PATD and differences in the time responsiveness of the 2 modalities. In addition, PATD only measures right ventricular output, excluding the bronchial circulation. For this reason, Rotcajg et al. [116] considered 20\% bias and precision as acceptable.

Smaller studies comparing NICOM with PICCO and Vigileo devices report similar capabilities between the devices $[116,118]$.

12.2. Limitations. The assumption that the area under the flow pulse is proportional to the product of peak flow and VET may not be valid under periods of low flow, and readings may have decreased accuracy [115].

\section{Endotracheal Cardiac Output Monitor}

The endotracheal cardiac output monitor (ECOM; ConMed, Irvine, Calif, USA) measures CO using impedance 
plethysmography. The ascending aorta lies in close proximity to the trachea. Using the principle of bioimpedance, a low frequency current of $2 \mathrm{~mA}$ and $200 \mathrm{kHz}$ is delivered from electrodes attached to a standard endotracheal tube (ETT) [119].

The ECOM 6 3D endotracheal tube (ETT) is a standard ETT to which are attached three orthogonal pairs of sensing electrodes on the cuff. Current is delivered between an electrode on the shaft of ETT and the number three electrode on the balloon. The sensing electrodes on the cuff detect the change in impedance secondary to aortic blood flow. The three-dimensional array allows for up to twelve combinations of electrodes which may be used for measurement of flow. This compensates for positional and anatomical differences between the cuff and aorta [119].

A proprietary algorithm calculates SV based on impedance changes. Increased blood flow in the aorta leads to decreased impedance. Apart from CO, also displayed are HR, ECG waveforms, SV, CI, and SVR [120].

13.1. Limitations. Coronary blood flow, which represents about $4-5 \%$ of $\mathrm{CO}$ is not recorded. Electrocautery produces interference.

13.2. Validation Studies. The technology is not yet fully validated in humans. A porcine study found excellent correlation when compared with transit time flow probes [120]. A study in cardiac-surgery patients reported poor correlation with $\mathrm{TD}$, wide limits of agreement and a large percentage error [121].

\section{Ultrasound Dilution}

Ultrasound dilution (UD) is a minimally invasive technique, first introduced in 1995, and widely used in hemodialysis and in extracorporeal membrane oxygenation (ECMO) to measure shunt flow, vascular access recirculation and CO [122]. The technique uses isotonic saline as an indicator to measure hemodynamic variables.

The underlying principle is that blood ultrasound velocity is a function of total blood protein concentration, temperature and plasma average ion concentration. The injection of isotonic saline results in decreased blood ultrasound velocity, from which dilution curves can be produced [123]. The setup involves a disposable tubing, which is used to create an extracorporeal loop between existing peripheral arterial and central venous catheters. The arteriovenous loop is primed with heparinized saline. A roller pump circulates blood from the artery to the vein. Two reusable sensors are clamped onto the arterial venous limbs of the loop. These sensors measure the changes in blood ultrasound velocity and blood flow following a bolus of saline injected into the venous side. The $\mathrm{CO}$ calculation is based on the Stewart-Hamilton principle [123].

14.1. Validation Studies. Relatively few studies investigating the technology have been undertaken thus far. Galstyan et al. [122] compared CO and blood volumes using UD and
PiCCO technology in adult ICU patients and concluded that the two were equivalent and interchangeable in that patient population. PiCCO blood volumes were significantly higher. The technology appears to be able to be used in different patient population groups. Krivitski et al. [123] performed in vitro studies to confirm the ability of UD technology to measure small flows and volumes in pediatric patients and neonates. Tsutsui et al. [124] found good correlation with TD in patients undergoing abdominal surgery.

\section{Transesophageal Echocardiography}

Transesophageal echocardiography (TEE) is widely used in the perioperative setting for evaluating cardiac anatomy and function. Doppler techniques for the measurement of $\mathrm{CO}$ are most commonly based on Simpson's rule. Early operators made determinations using the pulmonary artery, which only reflects right ventricular CO. Two-dimensional echocardiography determined the cross-sectional area of the PA, which was multiplied by the integral of the instantaneous flow velocity, determined by pulsed wave Doppler in the plane of the cross section [125]. A drawback is difficulty visualizing the PA in a significant number of patients because it may be obscured by the left main stem bronchus.

The validated frequently used technique developed by Perrino et al. [126] determines the cross-sectional area of the left ventricular outflow tract $\left(\mathrm{CSA}_{\mathrm{LVOT}}\right)$ in a mid-esophageal aortic long axis view. Planimetry is used to measure the area of the aortic valve. To measure aortic blood flow, the probe is positioned in a transgastric short-axis view of the left ventricle at the mid-papillary level. The image array is rotated approximately $120^{\circ}$ to produce imaging of the LVOT and ascending aorta lying parallel to the ultrasound beam. Continuous-wave Doppler is used to measure aortic blood flow velocities at the level of the aortic valve. Doppler CO is calculated as a product of the velocity time integral, $\mathrm{CSA}_{\mathrm{LVOT}}$, and HR [127]. Another method described uses the transgastric, apical view to assess aortic blood flow. The ultrasound beam is oriented almost parallel to the aortic valve blood flow. Probe positioning for this view is technically challenging [61].

\section{Esophageal Doppler}

Esophageal Doppler (ED) utilizes a flexible probe, approximately the size of a nasogastric tube, at the tip of which is a transducer ( $4 \mathrm{MHz}$ continuous or $5 \mathrm{MHz}$ pulsed wave). The probe may be left in place for days to weeks in intubated, sedated, mechanically ventilated patients. When advanced to the mid-thoracic level, ideally between the 5th and 6th thoracic vertebrae, the device is parallel to and thus able to measure blood flow velocity in the descending aorta [128]. It is assumed that the aorta is a cylinder and flow is calculated by multiplying the cross-sectional area $\left(\mathrm{CS}_{\mathrm{a}}\right)$ by the velocity $\left(V_{f}\right)$. Since velocity changes with pulsatility of flow, $V_{f}$ is described as the area under the curve of a velocity-time graph [32]. The area is calculated as the integral of the velocity curve over time $(d V / d t)$ from the start to the end of aortic 
blood flow ( $T_{0}$ and $T_{1}$, resp.). This area, known as the stroke distance, is the distance travelled by the blood during systole $(\mathrm{cm})$. This value is multiplied by the $\mathrm{CSA}_{\mathrm{a}}$. The aortic area may be derived either from published nomograms or direct measurement [32]:

$$
\mathrm{CO}=\mathrm{HR} \times \mathrm{SV} .
$$

SV changes can be used to guide fluid administration. ED also has the capability of determining the corrected time flow (FTc), which is the systolic flow time corrected for an HR of $60 / \mathrm{min}$. This value, which represents the time from the beginning of the aortic waveform upstroke to its return to baseline, is used as a measure of cardiac preload. Good correlation with other techniques, such as pulmonary artery occlusion pressure, along with improved outcomes has been reported [129-132].

16.1. Limitations. Only descending aortic blood flow, which represents about $70 \%$ of total flow, is measured, and so a correction factor ( $K$-factor) must be added to compensate for the blood flow to aortic arch vessels. This flow ratio may vary with metabolic activity, between different organs and during hemodynamic instability, and the validity is questionable outside of young healthy patients [32]. An inconstant proportion of blood flow to the descending aorta may also occur in the setting of aortic coarctation, aortic cross clamp, and pregnancy. Turbulence due to thoracic aneurysms, aortic balloon pump, aortic valve disease interfere with the validity of results [133].

$\mathrm{CSA}_{\mathrm{a}}$ changes with variations in pulse pressure, vascular tone, aortic compliance, volume status, or catecholamine use. Direct measurement produces greater accuracy [32]. In 76 patients with acute circulatory failure, measurements of aortic blood flow before and after a fluid bolus revealed an underestimation of the response to the fluid bolus in a significant number of patients if readings were based on an estimated unchanged $\mathrm{CSA}_{a}$ as opposed to directly measured aortic velocity and $\mathrm{CSA}_{\mathrm{a}}$ [134]. Proper probe position is essential to accuracy of determination of $V_{f}$. The Doppler beam must be within $20^{\circ}$ of axial flow to obtain good measurement.

With respect to fluid management, interpretation of FTc may be complicated by its inverse relationship with SVR. In conditions of elevated SVR, such as heart failure or excessive vasopressor use, FTc is reduced and may prompt fluid administration. Other conditions, such as pericardial tamponade or mitral stenosis, where there is limited cardiac filling will produce a decreased FTc and again prompt further fluid administration in a scenario where the patient may already have optimal cardiac filling based on the starling curve. SV has thus been argued to be a preferable variable to monitor fluid status $[135,136]$.

16.2. Validation Studies. Multiple studies have compared the validity of ED for measurement of CO against PATD under varying conditions [129, 137-139]. Dark and Singer [139] published a meta-analysis of eleven studies in critically ill patients, finding a pooled median bias of $0.19 \mathrm{~L} / \mathrm{min}$ (range: $-0.69-2.0 \mathrm{~L} / \mathrm{min}$ ) for CO. Boulnois and Pechoux [140] reported the pooled limits of agreement for 3 studies including 90 patients under a range of flow states to be -2.21 to $2.33 \mathrm{~L} / \mathrm{min}$. Laupland and Bands [133], in a meta-analysis of 25 studies, concluded that ED was reliable, responsive to changes, was showed good agreement with low bias, however, the wide limits of agreement raised concerns about precision. The two techniques are therefore not thought to be interchangeable; however, ED may be used to track changes [137].

Improved patient outcome has been demonstrated by a number of investigators when ED is used in goal-directed fluid therapy. Sinclair et al. [132] reported ED-guided fluid loading resulted in greater improvements in SV and CO with fluid administration in study patients, as well as faster recovery and decreased LOS than in controls. Venn et al. [141] similarly reported reduced hypotension and faster recovery for ED-monitored patients undergoing femoral fracture repair, compared with controls who received central venous pressure monitoring. In patients having major elective surgery, Gan et al. [142] reported earlier return to bowel function and decreased incidence of postoperative nausea and vomiting. Mythen and Webb [131] found a decreased incidence of gut mucosal perfusion (measured by gastric tonometry), major complications, and decreased hospital and ICU stay in cardiac-surgery patients who received goaldirected colloid therapy guided by ED compared with standard management. Wakeling et al. [143] randomized $128 \mathrm{pa}-$ tients receiving colorectal surgery to fluid management with guided with ED or central venous pressure monitoring. Decreased hospital LOS and faster gut recovery were seen in the ED-guided group. Noblett et al. [144] reported shorter hospital stay and decreased morbidity in patients undergoing colorectal resection who received ED-guided fluid management. Additionally, the intervention group had lower levels of interleukin 6, which may be a reflection of improved bowel perfusion. Conway et al. [145] reported improved hemodynamics in patients having major bowel surgery and fewer ICU admissions. In trauma patients, ED-guided fluid therapy resulted in decreased blood lactate levels, reduced infectious complications and decreased hospital and ICU LOS [146]. A nurse delivered ED-guided fluid protocol in patients after-cardiac-surgery resulted in shortened hospital LOS [147].

\section{Conclusion}

Despite controversies, complications, and inherent errors in measurement, intermittent bolus PATD CO measurement continues to be the gold standard. Newer techniques provide less invasive alternatives and will be increasingly adopted over time; however, the currently available monitors are still unable to provide central circulation pressures or true mixed venous saturations and cannot replace the PAC [32]. Many minimally invasive techniques continue to suffer from decreased accuracy and reliability under periods of hemodynamic instability, and so few have reached the level of interchangeability with the PAC. Esophageal Doppler and pulse 
contour monitors have the advantage of being able to predict fluid responsiveness. Their use in GDT has already been shown to decrease postoperative morbidity, and the use of these technologies is anticipated to continue to lead to greater improvement in outcomes [32].

\section{References}

[1] C. Prys-Roberts, "The measurement of cardiac output," British Journal of Anaesthesia, vol. 41, no. 9, pp. 751-760, 1969.

[2] D. A. Reuter, C. Huang, T. Edrich, S. K. Shernan, and H. K. Eltzschig, "Cardiac output monitoring using indicatordilution techniques: basics, limits, and perspectives," Anesthesia and Analgesia, vol. 110, no. 3, pp. 799-811, 2010.

[3] L. T. Kadota, "Theory and application of thermodilution cardiac output measurement: a review," Heart and Lung, vol. 14, no. 6, pp. 605-616, 1985.

[4] G. N. Stewart, "The output of heart in dogs," American Journal of Physiology, vol. 57, pp. 27-50, 1921.

[5] G. N. Stewart, "Researches on the Circulation Time and on the Influences which affect it," The Journal of Physiology, vol. 22, no. 3, pp. 159-183, 1897.

[6] T. Nishikawa and S. Dohi, "Errors in the measurement of cardiac output by thermodilution," Canadian Journal of Anaesthesia, vol. 40, no. 2, pp. 142-153, 1993.

[7] H. J. Swan, W. Ganz, J. Forrester, H. Marcus, G. Diamond, and D. Chonette, "Catheterization of the heart in man with use of a flow-directed balloon-tipped catheter," New England Journal of Medicine, vol. 283, no. 9, pp. 447-451, 1970.

[8] P. Libby and E. Braunwald, Braunwald's Heart Disease, Elsevier Saunders, Philadelphia, Pa, USA, 2007.

[9] J. R. C. Jansen, "The thermodilution method for the clinical assessment of cardiac output," Intensive Care Medicine, vol. 21, no. 8, pp. 691-697, 1995.

[10] T. Nishikawa and S. Dohi, "Errors in the measurement of cardiac output by thermodilution," Canadian Journal of Anaesthesia, vol. 40, no. 2, pp. 142-153, 1993.

[11] W. Ganz, R. Donoso, H. S. Marcus, J. S. Forrester, and H. J. C. Swan, "A new technique for measurement of cardiac output by thermodilution in man," The American Journal of Cardiology, vol. 27, no. 4, pp. 392-396, 1971.

[12] C. W. Stetz, R. G. Miller, G. E. Kelly, and T. A. Raffin, "Reliability of the thermodilution method in the determination of cardiac output in clinical practice," American Review of Respiratory Disease, vol. 126, no. 6, pp. 1001-1004, 1982.

[13] U. Elkayam, R. Berkley, and S. Azen, "Cardiac output by thermodilution technique. Effect of injectate's volume and temperature on accuracy and reproducibility in the critically ill patient," Chest, vol. 84, no. 4, pp. 418-422, 1983.

[14] M. G. Bazaral, J. Petre, and R. Novoa, "Errors in thermodilution cardiac output measurements caused by rapid pulmonary artery temperature decreases after cardiopulmonary bypass," Anesthesiology, vol. 77, no. 1, pp. 31-37, 1992.

[15] A. B. J. Groeneveld, R. R. Berendsen, A. J. Schneider, I. A. Pneumatikos, L. A. Stokkel, and L. G. Thijs, "Effect of the mechanical ventilatory cycle on thermodilution right ventricular volumes and cardiac output," Journal of Applied Physiology, vol. 89, no. 1, pp. 89-96, 2000.

[16] R. D. Miller, Miller's Anesthesia: 2-Volume Set, Churchill Livingstone, 2004.

[17] A. B. Leibowitz and J. M. Oropello, "The pulmonary artery catheter in anesthesia practice in 2007: an historical overview with emphasis on the past 6 years," Seminars in Cardiothoracic and Vascular Anesthesia, vol. 11, no. 3, pp. 162-176, 2007.

[18] J. M. Gore, R. J. Goldberg, D. H. Spodick, J. S. Alpert, and J. E. Dalen, "A community-wide assessment of the use of pulmonary artery catheters in patients with acute myocardial infarction," Chest, vol. 92, no. 4, pp. 721-727, 1987.

[19] E. D. Robin, "Death by pulmonary artery flow-directed catheter (editorial). Time for a moratorium?" Chest, vol. 92, no. 4, pp. 727-731, 1987.

[20] A. F. Connors Jr., T. Speroff, N. V. Dawson et al., "The effectiveness of right heart catheterization in the initial care of critically ill patients," Journal of the American Medical Association, vol. 276, no. 11, pp. 889-897, 1996.

[21] G. R. Bernard, G. Sopko, F. Cerra et al., "Pulmonary artery catheterization and clinical outcomes: National Heart, Lung, and Blood Institute and Food and Drug Administration workshop report," Journal of the American Medical Association, vol. 283, no. 19, pp. 2568-2572, 2000.

[22] J. D. Sandham, R. D. Hull, R. Frederick Brant et al., "A randomized, controlled trial of the use of pulmonary-artery catheters in high-risk surgical patients," New England Journal of Medicine, vol. 348, no. 1, pp. 5-14, 2003.

[23] S. Harvey, D. A. Harrison, M. Singer et al., "Assessment of the clinical effectiveness of pulmonary artery catheters in management of patients in intensive care (PAC-Man): a randomised controlled trial," Lancet, vol. 366, no. 9484, pp. 472-477, 2005.

[24] D. T. Yu, R. Platt, P. N. Lanken et al., "Relationship of pulmonary artery catheter use to mortality and resource utilization in patients with severe sepsis," Critical Care Medicine, vol. 31, no. 12, pp. 2734-2741, 2003.

[25] A. P. Wheeler, G. R. Bernard, B. T. Thompson et al., "Pulmonary-artery versus central venous catheter to guide treatment of acute lung injury," New England Journal of Medicine, vol. 354, no. 21, pp. 2213-2224, 2006.

[26] C. Richard, J. Warszawski, N. Anguel et al., "Early use of the pulmonary artery catheter and outcomes in patients with shock and acute respiratory distress syndrome: a randomized controlled trial," Journal of the American Medical Association, vol. 290, no. 20, pp. 2713-2720, 2003.

[27] F. G. Resano, E. I. Kapetanakis, P. C. Hill, E. Haile, and P. J. Corso, "Clinical outcomes of low-risk patients undergoing beating-heart surgery with or without pulmonary artery catheterization," Journal of Cardiothoracic and Vascular Anesthesia, vol. 20, no. 3, pp. 300-306, 2006.

[28] J. A. Hill, D. F. Pauly, D. R. Olitsky et al., "Evaluation study of congestive heart failure and pulmonary artery catheterization effectiveness," Journal of the American Medical Association, vol. 294, no. 13, pp. 1625-1633, 2005.

[29] L. A. Allen, J. G. Rogers, J. W. Warnica et al., "High mortality without ESCAPE: the registry of heart failure patients receiving pulmonary artery catheters without randomization," Journal of Cardiac Failure, vol. 14, no. 8, pp. 661-669, 2008.

[30] C. V. Leier, "Invasive hemodynamic monitoring the aftermath of the ESCAPE trial," Cardiology Clinics, vol. 25, no. 4, pp. 565-571, 2007.

[31] K. Chatterjee, "The Swan-Ganz catheters: past, present, and future: a viewpoint," Circulation, vol. 119, no. 1, pp. 147-152, 2009.

[32] D. J. Funk, E. W. Moretti, and T. J. Gan, "Minimally invasive cardiac output monitoring in the perioperative setting," Anesthesia and Analgesia, vol. 108, no. 3, pp. 887-897, 2009. 
[33] L. A. H. Critchley and J. A. J. H. Critchley, "A meta-analysis of studies using bias and precision statistics to compare cardiac output measurement techniques," Journal of Clinical Monitoring and Computing, vol. 15, no. 2, pp. 85-91, 1999.

[34] A. Rhodes and R. Sunderland, "Arterial pulse power analysis: the LiDCOTM plus system," in Functional Hemodynamic Monitoring (Update in Intensive Care Medicine), pp. 183-192, Springer, Berlin, Germany, 2005.

[35] R. A. F. Linton, D. M. Band, and K. M. Haire, "A new method of measuring cardiac output in man using lithium dilution," British Journal of Anaesthesia, vol. 71, no. 2, pp. 262-266, 1993.

[36] C. Garcia-Rodriguez, J. Pittman, C. H. Cassell et al., "Lithium dilution cardiac output measurement: a clinical assessment of central venous and peripheral venous indicator injection," Critical Care Medicine, vol. 30, no. 10, pp. 2199-2204, 2002.

[37] J. Mayer, J. Boldt, R. Poland, A. Peterson, and G. R. Manecke, "Continuous arterial pressure waveform-based cardiac output using the FloTrac/Vigileo: a review and metaanalysis," Journal of Cardiothoracic and Vascular Anesthesia, vol. 23, no. 3, pp. 401-406, 2009.

[38] M. Cecconi, D. Dawson, R. M. Grounds, and A. Rhodes, "Lithium dilution cardiac output measurement in the critically ill patient: determination of precision of the technique," Intensive Care Medicine, vol. 35, no. 3, pp. 498-504, 2009.

[39] S. Sundar and P. Panzica, "LiDCO systems," International Anesthesiology Clinics, vol. 48, no. 1, pp. 87-100, 2010.

[40] M. Jonas, "Haemodynamic optimisation of the surgical patient revisited," Anaesthesia International, vol. 2, pp. 19-23, 2008.

[41] T. T. Hamilton, L. M. Huber, and M. E. Jessen, "PulseCO: a less-invasive method to monitor cardiac output from arterial pressure after cardiac surgery," Annals of Thoracic Surgery, vol. 74, no. 4, pp. S1408-S1412, 2002.

[42] M. Cecconi, J. Fawcett, R. M. Grounds, and A. Rhodes, "A prospective study to evaluate the accuracy of pulse power analysis to monitor cardiac output in critically ill patients," BMC Anesthesiology, vol. 8, article no. 3, 2008.

[43] J. J. Kim, W. J. Dreyer, A. C. Chang, J. P. Breinholt, and R. G. Grifka, "Arterial pulse wave analysis: an accurate means of determining cardiac output in children," Pediatric Critical Care Medicine, vol. 7, no. 6, pp. 532-535, 2006.

[44] C. Missant, S. Rex, and P. F. Wouters, "Accuracy of cardiac output measurements with pulse contour analysis $\left(\mathrm{PulseCO}{ }^{\mathrm{TM}}\right)$ and Doppler echocardiography during offpump coronary artery bypass grafting," European Journal of Anaesthesiology, vol. 25, no. 3, pp. 243-248, 2008.

[45] J. V. McCoy, S. M. Hollenberg, R. P. Dellinger et al., "Continuous cardiac index monitoring: a prospective observational study of agreement between a pulmonary artery catheter and a calibrated minimally invasive technique," Resuscitation, vol. 80, no. 8, pp. 893-897, 2009.

[46] K. Yamashita, T. Nishiyama, T. Yokoyama, H. Abe, and M. Manabe, "Effects of vasodilation on cardiac output measured by PulseCO ${ }^{\mathrm{TM}}$," Journal of Clinical Monitoring and Computing, vol. 21, no. 6, pp. 335-339, 2007.

[47] M. G. Costa, G. Della Rocca, P. Chiarandini et al., "Continuous and intermittent cardiac output measurement in hyperdynamic conditions: pulmonary artery catheter vs. lithium dilution technique," Intensive Care Medicine, vol. 34, no. 2, pp. 257-263, 2008.

[48] J. J. Kim, W. J. Dreyer, A. C. Chang, J. P. Breinholt, and R. G. Grifka, "Arterial pulse wave analysis: an accurate means of determining cardiac output in children," Pediatric Critical Care Medicine, vol. 7, no. 6, pp. 532-535, 2006.

[49] R. A. Linton, M. M. Jonas, S. M. Tibby et al., "Cardiac output measured by lithium dilution and transpulmonary thermodilution in patients in a paediatric intensive care unit," Intensive Care Medicine, vol. 26, no. 10, pp. 1507-1511, 2000.

[50] R. Pearse, D. Dawson, J. Fawcett, A. Rhodes, R. M. Grounds, and E. D. Bennett, "Early goal-directed therapy after major surgery reduces complications and duration of hospital stay. A randomised, controlled trial [ISRCTN38797445]," Critical Care, vol. 9, no. 6, pp. R687-R693, 2005.

[51] M. G. Costa, A. Cecconi, L. Sheju, P. Chiarandini, L. Pompei, and G. Della Rocca, "Uncalibrated arterial pulse analysis cardiac output obtained with LiDCO Rapid versus PAC Thermodilution technique," Intensive Care Medicine, vol. 35, supplement 1, pp. S5-S306, 2009.

[52] K. Abdel-Galil, D. Craske, and J. McCaul, "Optimisation of intraoperative haemodynamics: early experience of its use in major head and neck surgery," British Journal of Oral and Maxillofacial Surgery, vol. 48, no. 3, pp. 189-191, 2010.

[53] L. Wijayasiri, D. Garewal, M. Khpal, A. Rhodes, A. Dewhurst, and M. Cecconi, "Does stroke volume increase after a fluid challenge? A study on the management of patients undergoing major head and neck free flap surgery: preliminary data," Critical Care, vol. 14, article P119, 2010.

[54] E. Barbon, F. Caliandro, J. Kamdar et al., "Dynamic indices of preload in postcardiac surgery patients by pulse power analysis," Critical Care, vol. 15, article P54, 2011.

[55] R. Pearse, "Optimisation of peri-operative cardiovascular management to improve surgical outcome," UK Clinical Research Network Study Portfolio, 2011, http://public .ukcrn.org.uk/search/StudyDetail.aspx?StudyID=6307.

[56] C. K. Hofera, M. Cecconib, G. Marxc, and G. Della Roccad, "Minimally invasive haemodynamic monitoring," European Journal of Anaesthesiology, vol. 26, no. 12, pp. 996-1002, 2009.

[57] K. H. Wesseling, R. Purschke, and N. T. Smith, "A computer module for the continuous monitoring of cardiac output in the operating theatre and the ICU," Acta Anaesthesiologica Belgica, vol. 27, pp. 327-341, 1976.

[58] J. Mayer and S. Suttner, "Cardiac output derived from arterial pressure waveform," Current Opinion in Anaesthesiology, vol. 22, no. 6, pp. 804-808, 2009.

[59] O. Hamzaoui, X. Monnet, C. Richard, D. Osman, D. Chemla, and J. L. Teboul, "Effects of changes in vascular tone on the agreement between pulse contour and transpulmonary thermodilution cardiac output measurements within an up to 6-hour calibration-free period," Critical Care Medicine, vol. 36, no. 2, pp. 434-440, 2008.

[60] PULSION Medical Inc, "Training documents—advanced hemodynamic monitoring," August 2009, http://www3.pulsion.de/fileadmin/pulsion_share/Education/Training/Train theTrainer/TtT_MPI851405US_R00_101008_Parameters.pdf.

[61] L. Mathews and R. K. Singh, "Cardiac output monitoring," Annals of Cardiac Anaesthesia, vol. 11, no. 1, pp. 56-68, 2008.

[62] W. Buhre, A. Weyland, S. Kazmaier et al., "Comparison of cardiac output assessed by pulse-contour analysis and thermodilution in patients undergoing minimally invasive direct coronary artery bypass grafting," Journal of Cardiothoracic and Vascular Anesthesia, vol. 13, no. 4, pp. 437-440, 1999.

[63] M. Chakravarthy, T. A. Patil, K. Jayaprakash, P. Kalligudd, D. Prabhakumar, and V. Jawali, "Comparison of simultaneous estimation of cardiac output by four techniques 
in patients undergoing off-pump coronary artery bypass surgery-a prospective observational study," Annals of Cardiac Anaesthesia, vol. 10, no. 2, pp. 121-126, 2007.

[64] O. Goedje, K. Hoeke, M. Lichtwarck-Aschoff, A. Faltchauser, P. Lamm, and B. Reichart, "Continuous cardiac output by femoral arterial thermodilution calibrated pulse contour analysis: comparison with pulmonary arterial thermodilution," Critical Care Medicine, vol. 27, no. 11, pp. 2407-2412, 1999.

[65] C. Wiesenack, C. Prasser, C. Keyl, and G. Rödig, "Assessment of intrathoracic blood volume as an indicator of cardiac preload: single transpulmonary thermodilution technique versus assessment of pressure preload parameters derived from a pulmonary artery catheter," Journal of Cardiothoracic and Vascular Anesthesia, vol. 15, no. 5, pp. 584-588, 2001.

[66] P. J. Peyton and S. W. Chong, "Minimally invasive measurement of cardiac output during surgery and critical care: a meta-analysis of accuracy and precision," Anesthesiology, vol. 113, no. 5, pp. 1220-1235, 2010.

[67] P. S. Halvorsen, A. Sokolov, M. Cvancarova, P. K. Hol, R. Lundblad, and T. I. Tønnessen, "Continuous cardiac output during off-pump coronary artery bypass surgery: pulsecontour analyses vs pulmonary artery thermodilution," British Journal of Anaesthesia, vol. 99, no. 4, pp. 484-492, 2007.

[68] G. Della Rocca, M. G. Costa, C. Coccia et al., "Cardiac output monitoring: aortic transpulmonary thermodilution and pulse contour analysis agree with standard thermodilution methods in patients undergoing lung transplantation," Canadian Journal of Anesthesia, vol. 50, no. 7, pp. 707-711, 2003.

[69] M. Boyle, J. Lawrence, A. Belessis, M. Murgo, and Y. Shehabi, "Comparison of dynamic measurements of pulse contour with pulsed heat continuous cardiac output in postoperative cardiac surgical patients," Australian Critical Care, vol. 20, no. 1, pp. 27-32, 2007.

[70] M. V. Küntscher, S. Blome-Eberwein, M. Pelzer, D. Erdmann, and G. Germann, "Transcardiopulmonary vs pulmonary arterial thermodilution methods for hemodynamic monitoring of burned patients," Journal of Burn Care and Rehabilitation, vol. 23, no. 1, pp. 21-26, 2002.

[71] J. B. Hamm, B. V. Nguyen, G. Kiss et al., "Assessment of a cardiac output device using arterial pulse waveform analysis, Vigileo $^{\mathrm{TM}}$, in cardiac surgery compared to pulmonary arterial thermodilution," Anaesthesia and Intensive Care, vol. 38, no. 2, pp. 295-301, 2010.

[72] Edwards Lifesciences LLC, "FloTrac system 3rd generation software: The next generation in hemodynamic management," December 2010, http://www.edwards.com/sitecollectionimages/products/mininvasive/ar04099.pdf.

[73] D. De Backer, G. Marx, A. Tan et al., "Arterial pressure-based cardiac output monitoring: a multicenter validation of the third-generation software in septic patients," Intensive Care Medicine, vol. 37, no. 2, pp. 233-240, 2011.

[74] F. D. Compton, B. Zukunft, C. Hoffmann, W. Zidek, and J. H. Schaefer, "Performance of a minimally invasive uncalibrated cardiac output monitoring system (Flotrac ${ }^{\mathrm{TM}} /$ Vigileo $^{\mathrm{TM}}$ ) in haemodynamically unstable patients," British Journal of Anaesthesia, vol. 100, no. 4, pp. 451-456, 2008.

[75] J. Mayer, J. Boldt, R. Beschmann, A. Stephan, and S. Suttner, "Uncalibrated arterial pressure waveform analysis for lessinvasive cardiac output determination in obese patients undergoing cardiac surgery," British Journal of Anaesthesia, vol. 103, no. 2, pp. 185-190, 2009.
[76] F. Compton, M. Wittrock, J.-H. Schaefer, W. Zidek, M. Tepel, and A. Scholze, "Noninvasive cardiac output determination using applanation tonometry-derived radial artery pulse contour analysis in critically ill patients," Anesthesia and Analgesia, vol. 106, no. 1, pp. 171-174, 2008.

[77] G. R. Manecke and W. R. Auger, "Cardiac output determination from the arterial pressure wave: clinical testing of a novel algorithm that does not require calibration," Journal of Cardiothoracic and Vascular Anesthesia, vol. 21, no. 1, pp. 3-7, 2007.

[78] W. T. McGee, J. L. Horswell, J. Calderon et al., "Validation of a continuous, arterial pressure-based cardiac output measurement: a multicenter, prospective clinical trial," Critical Care, vol. 11, no. 5, article no. R105, 2007.

[79] G. Biancofiore, L. A. H. Critchley, A. Lee et al., "Evaluation of an uncalibrated arterial pulse contour cardiac output monitoring system in cirrhotic patients undergoing liver surgery," British Journal of Anaesthesia, vol. 102, no. 1, pp. 47-54, 2009.

[80] B. Matthieu, N. -G. Karine, C. Vincent et al., "Cardiac output measurement in patients undergoing liver transplantation: pulmonary artery catheter versus uncalibrated arterial pressure waveform analysis," Anesthesia and Analgesia, vol. 106, no. 5, pp. 1480-1486, 2008.

[81] V. Krejci, A. Vannucci, A. Abbas, W. Chapman, and I. M. Kangrga, "Comparison of calibrated and uncalibrated arterial pressure-based cardiac output monitors during orthotopic liver transplantation," Liver Transplantation, vol. 16, no. 6, pp. 773-782, 2010.

[82] S. G. Sakka, J. Kozieras, O. Thuemer, and N. van Hout, "Measurement of cardiac output: a comparison between transpulmonary thermodilution and uncalibrated pulse contour analysis," British Journal of Anaesthesia, vol. 99, no. 3, pp. 337-342, 2007.

[83] J. Mayer, J. Boldt, T. Schöllhorn, K. D. Röhm, A. M. Mengistu, and S. Suttner, "Semi-invasive monitoring of cardiac output by a new device using arterial pressure waveform analysis: a comparison with intermittent pulmonary artery thermodilution in patients undergoing cardiac surgery," British Journal of Anaesthesia, vol. 98, no. 2, pp. 176-182, 2007.

[84] J. Mayer, J. Boldt, M. W. Wolf, J. Lang, and S. Suttner, "Cardiac output derived from arterial pressure waveform analysis in patients undergoing cardiac surgery: validity of a second generation device," Anesthesia and Analgesia, vol. 106, no. 3, pp. 867-872, 2008.

[85] C. K. Hofer, A. Senn, L. Weibel, and A. Zollinger, "Assessment of stroke volume variation for prediction of fluid responsiveness using the modified FloTrac ${ }^{\mathrm{TM}}$ and PiCCOplus ${ }^{\mathrm{TM}}$ system," Critical Care, vol. 12, no. 3, article no. R82, 2008.

[86] K. Suehiro and R. Okutani, "Stroke volume variation as a predictor of fluid responsiveness in patients undergoing one-lung ventilation," Journal of Cardiothoracic and Vascular Anesthesia, vol. 24, no. 5, pp. 772-775, 2010.

[87] J. Mayer, J. Boldt, A. M. Mengistu, K. D. Röhm, and S. Suttner, "Goal-directed intraoperative therapy based on autocalibrated arterial pressure waveform analysis reduces hospital stay in high-risk surgical patients: a randomized, controlled trial," Critical Care, vol. 14, no. 1, article R18, 2010.

[88] J. A. Alhashemi, M. Cecconi, G. Della Rocca, M. Cannesson, and C. K. Hofer, "Minimally invasive monitoring of cardiac output in the cardiac surgery intensive care unit," Current Heart Failure Reports, vol. 7, no. 3, pp. 116-124, 2010. 
[89] J. M. Ng, M. Y. Chow, P. C. Ip-Yam, M. H. Goh, and T. Agasthian, "Evaluation of partial carbon dioxide rebreathing cardiac output measurement during thoracic surgery," Journal of Cardiothoracic and Vascular Anesthesia, vol. 21, no. 5, pp. 655-658, 2007.

[90] Y. Kotake, T. Yamada, H. Nagata et al., "Improved accuracy of cardiac output estimation by the partial CO rebreathing method," Journal of Clinical Monitoring and Computing, vol. 23, no. 3, pp. 149-155, 2009.

[91] Y. Kotake, K. Moriyama, Y. Innami et al., "Performance of noninvasive partial $\mathrm{CO}_{2}$ rebreathing cardiac output and continuous thermodilution cardiac output in patients undergoing aortic reconstruction surgery," Anesthesiology, vol. 99, no. 2, pp. 283-288, 2003.

[92] G. Gueret, G. Kiss, B. Rossignol et al., "Cardiac output measurements in off-pump coronary surgery: comparison between NICO and the Swan-Ganz catheter," European Journal of Anaesthesiology, vol. 23, no. 10, pp. 848-854, 2006.

[93] M. Botero, D. Kirby, E. B. Lobato, E. D. Staples, and N. Gravenstein, "Measurement of cardiac output before and after cardiopulmonary bypass: comparison among aortic transit-time ultrasound, thermodilution, and noninvasive partial $\mathrm{CO}_{2}$ rebreathing," Journal of Cardiothoracic and Vascular Anesthesia, vol. 18, no. 5, pp. 563-572, 2004.

[94] H. Odenstedt, O. Stenqvist, and S. Lundin, "Clinical evaluation of a partial $\mathrm{CO}_{2}$ rebreathing technique for cardiac output monitoring in critically ill patients," Acta Anaesthesiologica Scandinavica, vol. 46, no. 2, pp. 152-159, 2002.

[95] F. Mielck, W. Buhre, G. Hanekop, T. Tirilomis, R. Hilgers, and H. Sonntag, "Comparison of continuous cardiac output measurements in patients after cardiac surgery," Journal of Cardiothoracic and Vascular Anesthesia, vol. 17, no. 2, pp. 211-216, 2003.

[96] P. V. Van Heerden, S. Baker, S. I. Lim, C. Weidman, and M. Bulsara, "Clinical evaluation of the Non-invasive Cardiac Output (NICO) monitor in the intensive care unit," Anaesthesia and Intensive Care, vol. 28, no. 4, pp. 427-430, 2000.

[97] L. B. Nilsson, N. Eldrup, and P. G. Berthelsen, "Lack of agreement between thermodilution and carbon dioxiderebreathing cardiac output," Acta Anaesthesiologica Scandinavica, vol. 45, no. 6, pp. 680-685, 2001.

[98] M. Rocco, G. Spadetta, A. Morelli et al., "A comparative evaluation of thermodilution and partial $\mathrm{CO}_{2}$ rebreathing techniques for cardiac output assessment in critically ill patients during assisted ventilation," Intensive Care Medicine, vol. 30, no. 1, pp. 82-87, 2004.

[99] W. G. Kubicek, J. N. Karnegis, R. P. Patterson, D. A. Witsoe, and R. H. Mattson, "Development and evaluation of an impedance cardiac output system," Aerospace Medicine, vol. 37, no. 12, pp. 1208-1212, 1966.

[100] W. C. Shoemaker, C. C. J. Wo, M. H. Bishop et al., "Multicenter trial of a new thoracic electrical bioimpedance device for cardiac output estimation," Critical Care Medicine, vol. 22, no. 12, pp. 1907-1912, 1994.

[101] Z. Lababidi, D. A. Ehmke, R. E. Durnin, P. E. Leaverton, and R. M. Lauer, "The first derivative thoracic impedance cardiogram," Circulation, vol. 41, no. 4, pp. 651-658, 1970.

[102] W. C. Shoemaker, H. Belzberg, C. C. J. Wo et al., "Multicenter study of noninvasive monitoring systems as alternatives to invasive monitoring of acutely ill emergency patients," Chest, vol. 114, no. 6, pp. 1643-1652, 1998.

[103] T. N. Sathyaprabha, C. Pradhan, G. Rashmi, K. Thennarasu, and T. R. Raju, "Noninvasive cardiac output measurement by transthoracic electrical bioimpedence: influence of age and gender," Journal of Clinical Monitoring and Computing, vol. 22, no. 6, pp. 401-408, 2008.

[104] A. R. Gujjar, K. Muralidhar, S. Banakal, R. Gupta, T. N. Sathyaprabha, and P. S. Jairaj, "Non-invasive cardiac output by transthoracic electrical bioimpedence in post-cardiac surgery patients: comparison with thermodilution method," Journal of Clinical Monitoring and Computing, vol. 22, no. 3, pp. 175-180, 2008.

[105] E. Barin, D. G. Haryadi, S. I. Schookin et al., "Evaluation of a thoracic bioimpedance cardiac output monitor during cardiac catheterization," Critical Care Medicine, vol. 28, no. 3, pp. 698-702, 2000.

[106] P. L. Appel, H. B. Kram, and J. MacKabee, "Comparison of measurements of cardiac output by bioimpedance and thermodilution in severely ill surgical patients," Critical Care Medicine, vol. 14, no. 11, pp. 933-935, 1986.

[107] T. V. Clancy, K. Norman, R. Reynolds, D. Covington, and J. G. Maxwell, "Cardiac output measurement in critical care patients: thoracic electrical bioimpedance versus thermodilution," Journal of Trauma, vol. 31, no. 8, pp. 1116-1121, 1991.

[108] K. L. Wong and P. C. Hou, "The accuracy of bioimpedance cardiography in the measurement of cardiac output in comparison with thermodilution method," Acta Anaesthesiologica Sinica, vol. 34, no. 2, pp. 55-59, 1996.

[109] J. M. Van De Water, T. W. Miller, R. L. Vogel, B. E. Mount, and M. L. Dalton, "Impedance cardiography the next vital sign technology?” Chest, vol. 123, no. 6, pp. 2028-2033, 2003.

[110] T. Kööbi, M. Kähönen, M. Koskinen, S. Kaukinen, and V. M. H. Turjanmaa, "Comparison of bioimpedance and radioisotope methods in the estimation of extracellular water volume before and after coronary artery bypass grafting operation," Clinical Physiology, vol. 20, no. 4, pp. 283-291, 2000.

[111] B. D. Spiess, M. A. Patel, L. O. Soltow, and I. H. Wright, "Comparison of bioimpedance versus thermodilution cardiac output during cardiac surgery: evaluation of a secondgeneration bioimpedance device," Journal of Cardiothoracic and Vascular Anesthesia, vol. 15, no. 5, pp. 567-573, 2001.

[112] F. G. Spinale, H. D. Reines, and F. A. Crawford, "Comparison of bioimpedance and thermodilution methods for determining cardiac output: experimental and clinical studies: updated in 1995," Annals of Thoracic Surgery, vol. 60, no. 2, pp. 483-484, 1995.

[113] P. Zácek, P. Kunes, E. Kobzová, and J. Dominik, “Thoracic electrical bioimpedance versus thermodilution in patients post open-heart surgery," Acta Medica (Hradec Králové), vol. 42, no. 1, pp. 19-23, 1999.

[114] M. M. Hirschl, H. Kittler, C. Woisetschläger et al., "Simultaneous comparison of thoracic bioimpedance and arterial pulse waveform-derived cardiac output with thermodilution measurement," Critical Care Medicine, vol. 28, no. 6, pp. 1798-1802, 2000.

[115] H. Keren, D. Burkhoff, and P. Squara, "Evaluation of a noninvasive continuous cardiac output monitoring system based on thoracic bioreactance," American Journal of Physiology, vol. 293, no. 1, pp. H583-H589, 2007.

[116] D. Rotcajg, D. Denjean, P. Estagnasie, A. Brusset, and P. Squara, "Comparison of monitoring performance of Bioreactance vs. pulse contour during lung recruitment maneuvers," Critical Care, vol. 13, no. 4, article no. R125, 2009. 
[117] N. Y. Raval, P. Squara, M. Cleman, K. Yalamanchili, M. Winklmaier, and D. Burkhoff, "Multicenter evaluation of noninvasive cardiac output measurement by bioreactance technique," Journal of Clinical Monitoring and Computing, vol. 22, no. 2, pp. 113-119, 2008.

[118] S. Marqué, A. Cariou, J. D. Chiche, and P. Squara, "Comparison between Flotrac-Vigileo and Bioreactance, a totally noninvasive method for cardiac output monitoring," Critical Care, vol. 13, no. 3, article no. R73, 2009.

[119] CONMED Corporation, "ECOM endotracheal cardiac output monitor," 2010, http://www.conmed.com/products_ECOM.php.

[120] A. W. Wallace, A. Salahieh, A. Lawrence, K. Spector, C. Owens, and D. Alonso, "Endotracheal cardiac output monitor," Anesthesiology, vol. 92, no. 1, pp. 178-189, 2000.

[121] T. R. Ball, B. C. Culp, V. Patel, D. F. Gloyna, D. P. Ciceri, and W. C. Culp Jr., "Comparison of the endotracheal cardiac output monitor to thermodilution in cardiac surgery patients," Journal of Cardiothoracic and Vascular Anesthesia, vol. 24, no. 5, pp. 762-766, 2010.

[122] G. Galstyan, M. Bychinin, M. Alexanyan, and V. Gorodetsky, "Comparison of cardiac output and blood volumes in intrathoracic compartments measured by ultrasound dilution and transpulmonary thermodilution methods," Intensive Care Medicine, vol. 36, no. 12, pp. 2140-2144, 2010.

[123] N. M. Krivitski, V. V. Kislukhin, and N. V. Thuramalla, "Theory and in vitro validation of a new extracorporeal arteriovenous loop approach for hemodynamic assessment in pediatric and neonatal intensive care unit patients," Pediatric Critical Care Medicine, vol. 9, no. 4, pp. 423-428, 2008.

[124] M. Tsutsui, N. Matsuoka, T. Ikeda, Y. Sanjo, and T. Kazama, "Comparison of a new cardiac output ultrasound dilution method with thermodilution technique in adult patients under general anesthesia," Journal of Cardiothoracic and Vascular Anesthesia, vol. 23, no. 6, pp. 835-840, 2009.

[125] J. S. Savino, C. A. Troianos, S. Aukburg, R. Weiss, and N. Reichek, "Measurement of pulmonary blood flow with transesophageal two-dimensional and Doppler echocardiography," Anesthesiology, vol. 75, no. 3, pp. 445-451, 1991.

[126] A. C. Perrino Jr., S. N. Harris, and M. A. Luther, "Intraoperative determination of cardiac output using multiplane transesophageal echocardiography: a comparison to thermodilution," Anesthesiology, vol. 89, no. 2, pp. 350-357, 1998.

[127] M. R. Concha, V. F. Mertz, L. I. Cortínez, K. A. González, and J. M. Butte, "Pulse contour analysis and transesophageal echocardiography: a comparison of measurements of cardiac output during laparoscopic colon surgery," Anesthesia and Analgesia, vol. 109, no. 1, pp. 114-118, 2009.

[128] C. Berton and B. Cholley, "Equipment review: new techniques for cardiac output measurement-oesophageal Doppler, Fick principle using carbon dioxide, and pulse contour analysis," Critical Care, vol. 6, no. 3, pp. 216-221, 2002.

[129] C. J. Dicorte, P. Latham, P. E. Greilich, M. V. Cooley, P. A. Grayburn, and M. E. Jessen, "Esophageal doppler monitor determinations of cardiac output and preload during cardiac operations," Annals of Thoracic Surgery, vol. 69, no. 6, pp. 1782-1786, 2000.

[130] A. K. Madan, V. V. UyBarreta, S. Aliabadi-Wahle et al., "Esophageal doppler ultrasound monitor versus pulmonary artery catheter in the hemodynamic management of critically
III surgical patients," Journal of Trauma, vol. 46, no. 4, pp. 607-612, 1999.

[131] M. G. Mythen and A. R. Webb, "Perioperative plasma volume expansion reduces the incidence of gut mucosal hypoperfusion during cardiac surgery," Archives of Surgery, vol. 130, no. 4, pp. 423-429, 1995.

[132] S. Sinclair, S. James, and M. Singer, "Intraoperative intravascular volume optimisation and length of hospital stay after repair of proximal femoral fracture: randomised controlled trial," British Medical Journal, vol. 315, no. 7113, pp. 909-912, 1997.

[133] K. B. Laupland and C. J. Bands, "Utility of esophageal Doppler as a minimally invasive hemodynamic monitor: a review," Canadian Journal of Anesthesia, vol. 49, no. 4, pp. 393-401, 2002.

[134] X. Monnet, D. Chemla, D. Osman et al., "Measuring aortic diameter improves accuracy of esophageal Doppler in assessing fluid responsiveness," Critical Care Medicine, vol. 35, no. 2, pp. 477-482, 2007.

[135] M. Bundgaard-Nielsen, K. Holte, N. H. Secher, and H. Kehlet, "Monitoring of peri-operative fluid administration by individualized goal-directed therapy: review article," Acta Anaesthesiologica Scandinavica, vol. 51, no. 3, pp. 331-340, 2007.

[136] M. Singer, "The FTc is not an accurate marker of left ventricular preload," Intensive Care Medicine, vol. 32, no. 7, p. 1089, 2006.

[137] P. Schober, S. A. Loer, and L. A. Schwarte, "Perioperative hemodynamic monitoring with transesophageal doppler technology," Anesthesia and Analgesia, vol. 109, no. 2, pp. 340-353, 2009.

[138] M. Singer, “Cardiac output in 1998," Heart, vol. 79, no. 5, pp. 425-428, 1998.

[139] P. M. Dark and M. Singer, "The validity of trans-esophageal Doppler ultrasonography as a measure of cardiac output in critically ill adults," Intensive Care Medicine, vol. 30, no. 11, pp. 2060-2066, 2004.

[140] J. L. G. Boulnois and T. Pechoux, "Non-invasive cardiac output monitoring by aortic blood flow measurement with the Dynemo 3000," Journal of Clinical Monitoring and Computing, vol. 16, no. 2, pp. 127-140, 2000.

[141] R. Venn, A. Steele, P. Richardson, J. Poloniecki, M. Grounds, and P. Newman, "Randomized controlled trial to investigate influence of the fluid challenge on duration of hospital stay and perioperative morbidity in patients with hip fractures," British Journal of Anaesthesia, vol. 88, no. 1, pp. 65-71, 2002.

[142] T. J. Gan, A. Soppitt, M. Maroof et al., "Goal-directed intraoperative fluid administration reduces length of hospital stay after major surgery," Anesthesiology, vol. 97, no. 4, pp. 820-826, 2002.

[143] H. G. Wakeling, M. R. McFall, C. S. Jenkins et al., "Intraoperative oesophageal Doppler guided fluid management shortens postoperative hospital stay after major bowel surgery," British Journal of Anaesthesia, vol. 95, no. 5, pp. 634-642, 2005.

[144] S. E. Noblett, C. P. Snowden, B. K. Shenton, and A. F. Horgan, "Randomized clinical trial assessing the effect of Doppler-optimized fluid management on outcome after elective colorectal resection," British Journal of Surgery, vol. 93, no. 9, pp. 1069-1076, 2006.

[145] D. H. Conway, R. Mayall, M. S. Abdul-Latif, S. Gilligan, and C. Tackaberry, "Randomised controlled trial investigating the 
influence of intravenous fluid titration using oesophageal Doppler monitoring during bowel surgery," Anaesthesia, vol. 57, no. 9, pp. 845-849, 2002.

[146] I. Chytra, R. Pradl, R. Bosman, P. Pelnář, E. Kasal, and A. Židková, "Esophageal Doppler-guided fluid management decreases blood lactate levels in multiple-trauma patients: a randomized controlled trial," Critical Care, vol. 11, no. 1, article no. R24, 2007.

[147] M. McKendry, H. McGloin, D. Saberi, L. Caudwell, A. R. Brady, and M. Singer, "Randomised controlled trial assessing the impact of a nurse delivered, flow monitored protocol for optimisation of circulatory status after cardiac surgery," British Medical Journal, vol. 329, no. 7460, pp. 258-261, 2004. 


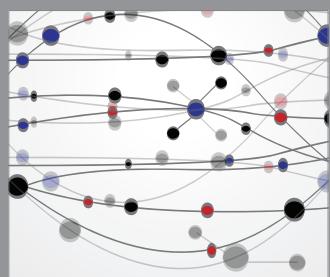

The Scientific World Journal
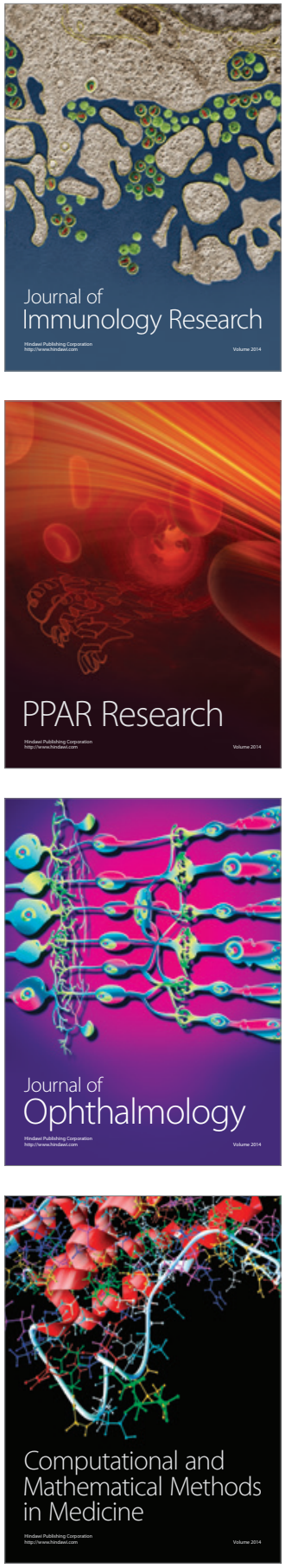

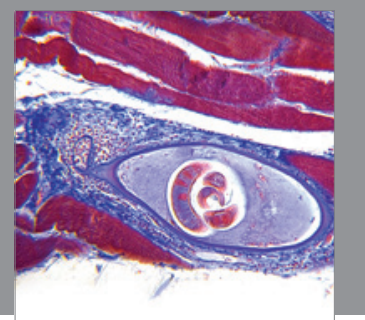

Gastroenterology

Research and Practice
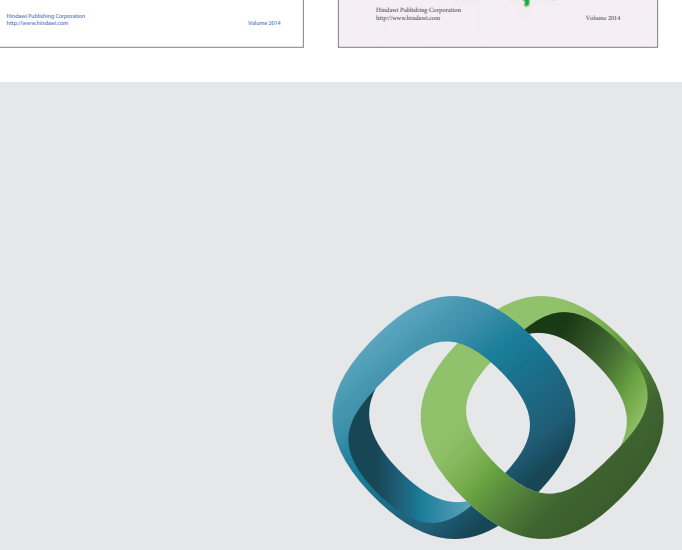

\section{Hindawi}

Submit your manuscripts at

http://www.hindawi.com
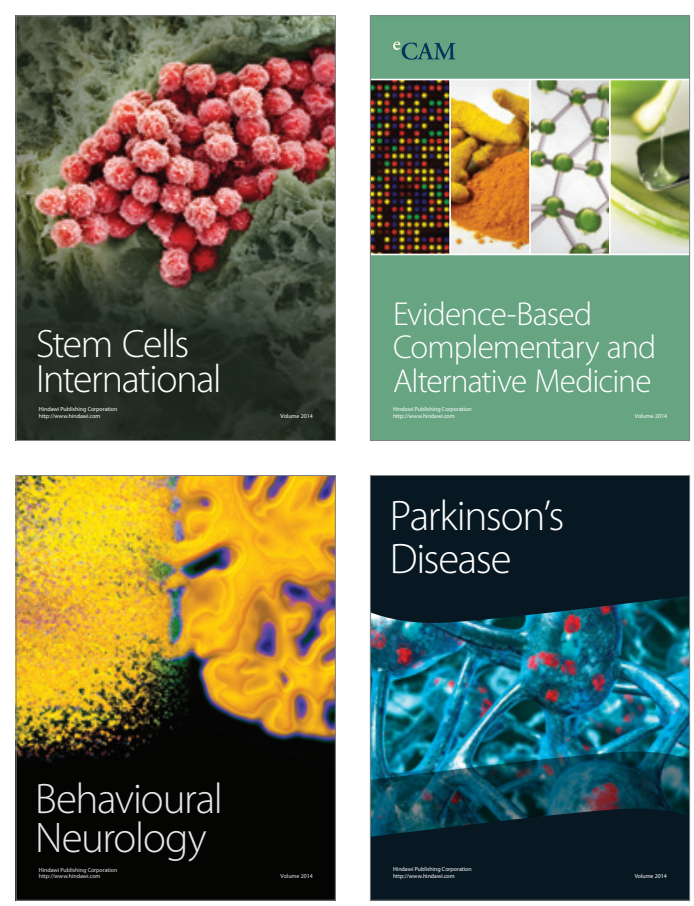

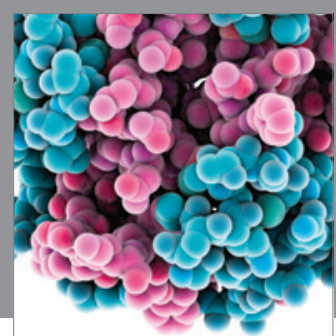

Journal of
Diabetes Research

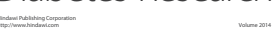

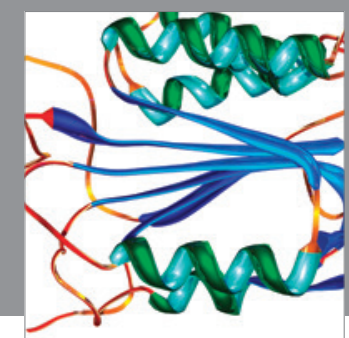

Disease Markers
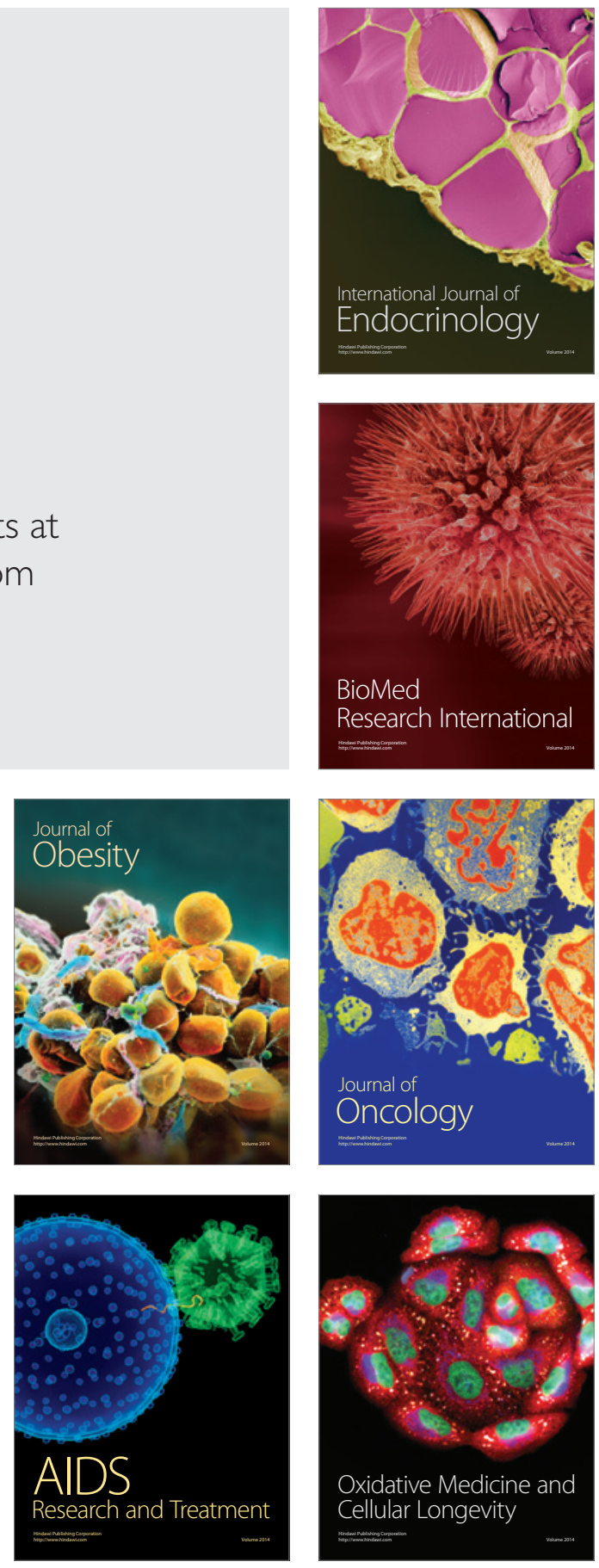